\title{
Constraining crustal emplacement processes from the variation in seismic layer 2A thickness at the East Pacific Rise
}

\author{
Emilie E.E. Hooft ${ }^{\mathrm{a}, *}$, Hans Schouten ${ }^{\mathrm{b}}$, Robert S. Detrick ${ }^{\mathrm{b}}$ \\ ${ }^{a}$ Massachusetts Institute of Technology / Woods Hole Oceanographic Institution Joint Program in Oceanography, Woods Hole, MA \\ 02543-1542, USA \\ ${ }^{\mathrm{b}}$ Department of Geology and Geophysics, Woods Hole Oceanographic Institution, Woods Hole, MA 02543-1542, USA
}

Received 11 December 1995; accepted 14 May 1996

\begin{abstract}
A stochastic model for the emplacement of dikes and lava flows at a fast spreading ridge can generate an upper oceanic crustal structure similar to that observed in seismic data from the East Pacific Rise (EPR), in ocean drill holes, and in ophiolites. In this model the location of successive dike intrusion events relative to the ridge axis is determined by a Gaussian probability function and the cumulative flow lengths of the erupted lavas are chosen to build a Gaussian-shaped lava pile. We interpret wide-angle seismic reflections from the steep velocity gradient at the base of seismic layer $2 \mathrm{~A}$ to be the extrusive/sheeted dike contact. Seismic data from the northern and southern EPR place constraints on the on-axis extrusive layer thickness $(230 \pm 50 \mathrm{~m})$, the distance over which the thickening of the extrusive layer occurs (width of the accretion zone $=1-3 \mathrm{~km}$ ) and its off-axis thickness $(300-800 \mathrm{~m}$ ). Ophiolites and ocean drill holes (DSDP Hole 504B) provide additional estimates of the thickness of the extrusive layer and constrain the thickness of the transition region from extrusives to sheeted dikes ( 100-200 m). A simple stochastic emplacement model, where the lavas are described by one mean flow length, fits the thickening of the extrusive layer off-axis inferred from the deepening of seismic layer $2 \mathrm{~A}$, but the predicted transition from sheeted dikes to extrusives is too thick. In order to match the dimensions and flat-topped shape of the seismic layer 2A boundary as well as the thickness of the extrusive-sheeted dike transition, a bimodal distribution of lava flows is used. Short flows, confined within the axial summit caldera (ASC), build up approximately half the extrusive volume. Occasional voluminous flows spill out of the ASC, or erupt outside of the ASC, and pond at a considerable distance off-axis to build up the remainder of the extrusive section. The upper part of the final extrusive section will be dominated by the off-axis flows, while the lower portions will be primarily composed of short flows erupted within the ASC. Magnetic transition widths predicted from the overlap of lavas $(\sim 2 \mathrm{~km})$ in this model are similar to those measured in deep-tow studies. Assuming a smoothing function which acts over one seismic wavelength, the upper crustal velocity structure predicted by the bimodal lava emplacement model is consistent with the shallow seismic velocity structure measured on the EPR. The ages of seafloor lavas in this model are younger than the tectonic spreading model ages by $\sim 30-70 \mathrm{kyr}$, in agreement with anomalously young lava ages obtained from radioisotope dating of seafloor basalts near the EPR.
\end{abstract}

Keywords: East Pacific Rise; emplacement; dikes; oceanic crust; models

${ }^{*}$ Corresponding author. Fax: +1 508457 2150. E-mail: emilie@ochre.whoi.edu 


\section{Introduction}

The upper portion of the oceanic crust is formed by dike intrusion and the eruption of lava flows. These two magmatic processes generate an upper crustal structure composed of lavas piled on top of one another, underlain by a sheeted dike complex. Constraints on the processes of upper crustal construction have come from ophiolite studies [1,2], observations in active rifts (e.g., Iceland [3]), modeling of marine magnetic anomaly shapes and transition thicknesses [4-8], mapping [9-14], dating [15], and drilling (e.g. DSDP Hole 504B [16]) of young ocean crust. Ophiolite studies, on the basis of chilled margin statistics $[1,17,18]$ and measurements of the thickness of the lava/dike transition [1] predict narrow intrusion zone widths of $10-50 \mathrm{~m}$. Modeling of marine magnetic anomaly transition widths suggests a lava emplacement zone 1-3 km wide. Geological mapping and dating of lava flows at the East Pacific Rise (EPR) suggest that volcanic activity is primarily confined within the narrow $(\sim 50-200 \mathrm{~m}$ wide) axial summit caldera (ASC), but there is evidence for very young flows on the flanks of the axial high outside the ASC that suggest eruptive activity over a much wider zone or transport of lavas a considerable distance off-axis (e.g. [19]). The relative importance of off-axis eruptive activity and the processes that control the thickness of the extrusive section are still poorly understood.

Advances in seismic imaging of the shallow velocity structure at the East Pacific Rise allow the thickness of what is commonly interpreted as the extrusive layer to be directly mapped. In this paper, we use the variation in this seismically determined extrusive thickness to provide new constraints on crustal emplacement processes. We show that the dike intrusion zone must be extremely localized about the ridge axis. The extrusive section is made up of two units of about equal thickness: a lower unit, composed of short flows confined within the axial summit caldera, and an upper unit, of flows which spill out of the axial summit caldera (ASC), or are channelled across the shoulders of the rise axis in lava tubes and flow long distances down the flanks of the axial high, or erupt off-axis. We discuss the implications of this emplacement model on the seismic velocity structure of the shallow oceanic crust, subsidence rates, dip of isochrons in the extrusive section, magnetic anomaly transition widths, and the age of lavas exposed at the seafloor.

\section{Observational constraints on upper oceanic crustal structure at the EPR}

The typical seismic velocity structure of the shallow oceanic crust has been characterized from high quality expanding spread profiles (ESP) [20,21], tomographic images [22], refraction data [23], wide aperture profiles (WAP) [24,25] and on-bottom refraction work (NOBEL) [26]. These studies have identified a small velocity layer which is $100-200 \mathrm{~m}$ thick, has velocities $\leq 2.6 \mathrm{~km} / \mathrm{s}$ and a low vertical velocity gradient. This surficial low velocity layer is underlain by a steep gradient zone where velocities $>\sim 5 \mathrm{~km} / \mathrm{s}$ are reached in a few hundred meters. The crustal section with the surficial low velocity layer and the underlying steep velocity gradient is called layer $2 \mathrm{~A}$. The underlying crust, with velocities $>\sim 5 \mathrm{~km} / \mathrm{s}$ and a very gradual velocity gradient, corresponds to layer 2B [27]. The base of the high gradient region is imaged in multichannel seismic reflection (MCS) experiments as a shallow wide angle reflection formed by refracted energy turning in the steep gradient $[24,28,29]$. No normal incidence reflection is seen, since there is no impedance contrast, rather the steep gradient generates diving rays which are observed at large offsets on the streamer. In Fig. 1b,d, the wide angle reflection from the base of layer $2 \mathrm{~A}$ is outlined with a gray line for two seismic profiles shot across the rise crest of the southern EPR (SEPR31 at $17^{\circ} 14^{\prime} \mathrm{S}$, and SEPR06 at $18^{\circ} 28^{\prime} \mathrm{S}$ ). To obtain the thickness of layer $2 \mathrm{~A}$ the two-way travel times to the base of layer $2 \mathrm{~A}$ are converted to depth using the composite velocity model of Harding et al. [28].

The shallow velocity structure of the ocean crust is controlled by the composition and porosity of the upper crust. We interpret layer $2 \mathrm{~A}$ in young $(<1$ My) oceanic crust to be the extrusive section and use measurements of its thickness to map the variability in the accumulation of extrusives. The surficial lowvelocity zone is attributed to a layer of high-porosity pillows and flows (e.g. [30,31]), with porosities possibly greater than $20 \%$ [32-34]. The higher-velocity 
a)

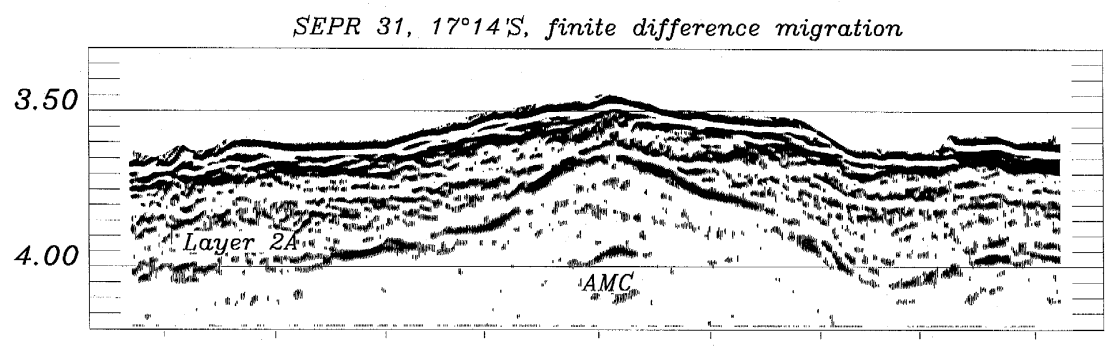

b)

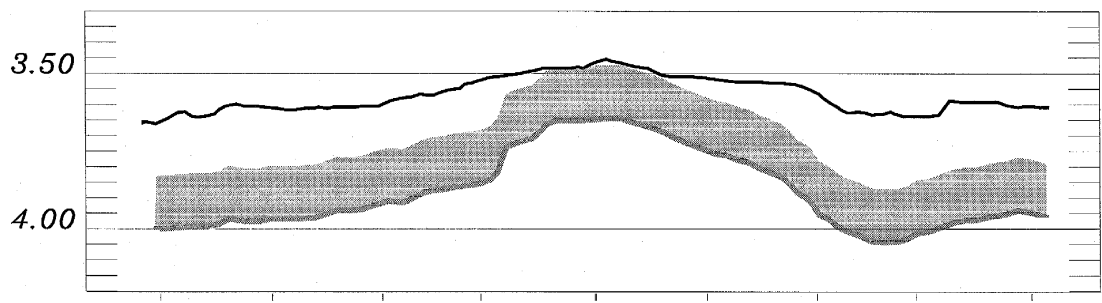

c) SEPR 6, $18^{\circ} 28^{\prime}$ 'S, finite difference migration

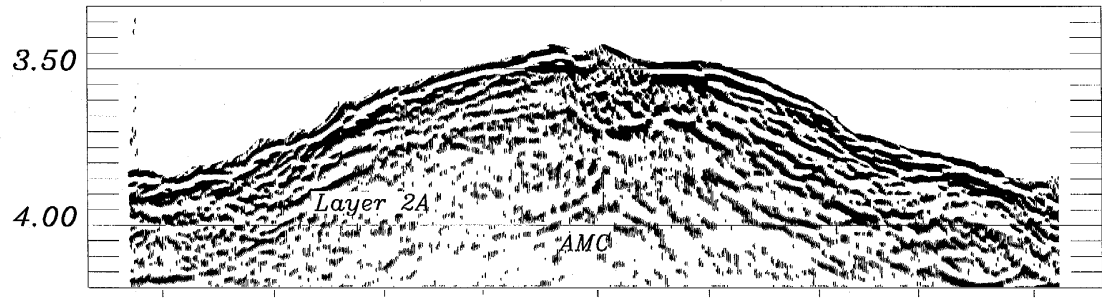

d)

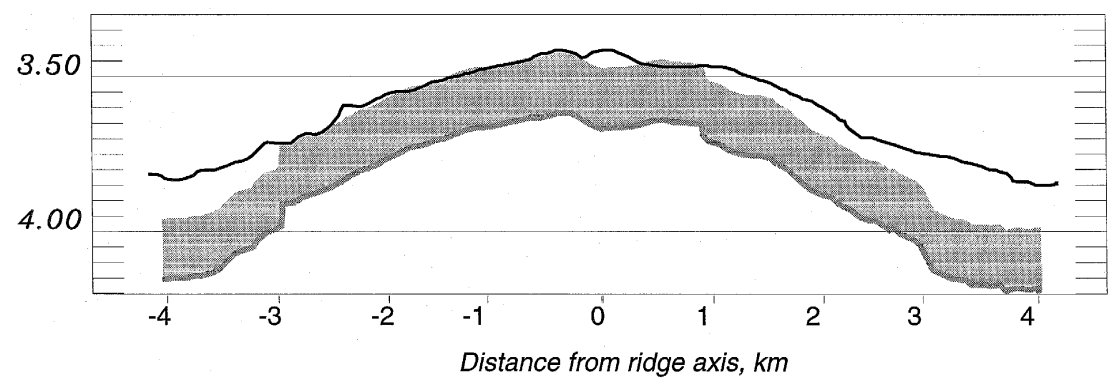

Fig. 1. (a) and (c) Across-axis multichannel seismic sections from the southern East Pacific Rise, SEPR31 (17 $\left.14^{\prime} \mathrm{S}\right)$ and SEPR06 (18 $\left.28^{\prime} \mathrm{S}\right)$ [40]. The data were stacked using a velocity-depth function that varied laterally and then finite difference migrated to account for the seafloor and layer 2A topography. The axial magma chamber (AMC) and the base of layer 2A are indicated on the figures. (b) and (d) Line drawings showing picks of the seafloor and layer $2 \mathrm{~A}$ reflections in black and dark gray lines, respectively. The light gray constant thickness band corresponds to the on-axis thickness of layer 2A. This emphasizes that the on-axis thickness is built up very rapidly, while the off-axis accretion of layer 2A occurs over a few kilometers. Both profiles show similar on-axis and off-axis layer $2 \mathrm{~A}$ thicknesses, $\sim 250 \mathrm{~m}$ and $500-550 \mathrm{~m}$, respectively. The two profiles represent end-members of the width of the region over which the accretion of layer $2 \mathrm{~A}$ takes place: on SEPR31 it is narrow while on SEPR06 it is broad and the widths of the 2A accretion zone are $1.2 \mathrm{~km}$ and $3 \mathrm{~km}$, respectively. Note that the layer $2 \mathrm{~A} / 2 \mathrm{~B}$ boundary has a flat-topped, concave shape beneath the rise axis. 
Table 1

Seismic constraints on the variability of layer $2 \mathrm{~A}$ along the EPR

\begin{tabular}{|c|c|c|c|}
\hline Experiment, latitude & On-axis 2A thickness & Off-axis $2 \mathrm{~A}$ thickness & $\begin{array}{l}\text { Thickness of } 2 \mathrm{~A} \\
\text { accretion zone }\end{array}$ \\
\hline MCS NEPR, $8^{\circ} 50^{\prime}-9^{\circ} 50^{\prime} \mathrm{N}^{a}$ & $\begin{array}{l}\sim 230 \pm 50 \mathrm{~m} \\
\sim 400 \mathrm{~m} \text { near } 9^{\circ} \mathrm{N} \text { OSC }\end{array}$ & $440-560 \mathrm{~m}$ & $0.8-2 \mathrm{~km}$ \\
\hline MCS SEPR, $13^{\circ}-20.5^{\circ} \mathrm{S}^{\mathrm{b}}$ & $\begin{array}{l}235 \pm 40 \mathrm{~m} \\
300-400 \mathrm{~m} \text { near OSCs }\end{array}$ & $400-800 \mathrm{~m}$ & $0.5-3 \mathrm{~km}$ \\
\hline WAP, $9^{\circ} 35^{\prime} \mathrm{N}^{\mathrm{c}}$ & $\sim 150 \pm 30 \mathrm{~m}$ & $250-280 \mathrm{~m}$ & $3 \mathrm{~km}$ \\
\hline $\mathrm{ESP}, 9^{\circ} 35^{\prime} \mathrm{N}^{\mathrm{d}}$ & $150 \mathrm{~m}$ & $310-350 \mathrm{~m}$ & \\
\hline NOBEL, $9^{\circ} 30^{\prime} \mathrm{N}^{\mathrm{e}}$ & $130 \mathrm{~m}$ & $\sim 300 \mathrm{~m}$ & \\
\hline
\end{tabular}

${ }^{a}$ Harding et al. [28]. ${ }^{\text {b }}$ Hooft et al. [41]. ${ }^{\mathrm{c}}$ Vera and Diebold [24]. ${ }^{\mathrm{d}}$ Vera et al. [20]. ${ }^{\mathrm{e}}$ Christeson et al. [36].

layer 2B material underlying the surficial low-velocity layer has been interpreted to be either the top of the sheeted dike sequence $[28,35,36]$ or low-porosity pillow lavas and flows $[20,21,23,37]$. At DSDP Hole 504B - 6 My old, intermediate spreading crust high seismic velocities are reached within the extrusive section [38]. At Hess Deep - young, fast spreading crust - the transition from extrusives to sheeted dikes occurs at a depth corresponding to the location of the base of layer $2 \mathrm{~A}$ in velocity-depth profiles measured on fast-spreading crust [26]. We follow the reasoning of Christeson et al., 1994 [27] in considering the velocity structure measured at DSDP Hole 504B to be the result of the alteration and reduction of bulk porosity of the shallow crust.
With increasing age the base of layer 2A migrates from the sheeted dike/extrusive boundary upwards to a porosity contrast within the extrusive section. By comparison with Hess Deep, we interpret layer 2A to consist of both the extrusive and mixed zones (i.e., it is a transition zone where lavas and sheeted dikes intermingle). The high velocity, low gradient material represents the top of the sheeted dike complex (layer 2B). The wide angle multichannel reflections are due to rays turning in the steep-velocity gradient in the transition zone at the base of layer $2 \mathrm{~A}$.

Large lateral variations in layer $2 \mathrm{~A}$ thickness are observed in multichannel seismic data at the fastspreading northern $[24,28]$ and southern $[29,39-41]$ $\mathrm{EPR}$, in wide aperture profiles [24] in the $9^{\circ} \mathrm{N}$ area,

Table 2

Geological observations

\begin{tabular}{|c|c|c|c|c|}
\hline \multicolumn{2}{|l|}{ Geology } & \multicolumn{3}{|l|}{ Observation } \\
\hline Type & Location & Spreading rate & $\begin{array}{l}\text { Extrusive } \\
\text { thickness }\end{array}$ & $\begin{array}{l}\text { Extrusive-dike } \\
\text { transition } \\
\text { thickness }\end{array}$ \\
\hline Ophiolites & $\begin{array}{l}\text { Betts Cove, Newfoundland } \\
\text { Bay of Islands, Newfoundland } \\
\text { Troodos, Cyprus } \\
\text { Semail, Oman }\end{array}$ & $\begin{array}{l}\text { slow } \\
\text { slow } \\
\text { intermediate } \\
\text { fast }\end{array}$ & $\begin{array}{l}1000 \mathrm{~m}^{\mathrm{b}} \\
\sim 700 \mathrm{~m}^{\mathrm{b}} \\
1100 \mathrm{~m}^{\mathrm{b}} \\
400-1600 \mathrm{~m}^{\mathrm{d}}\end{array}$ & $\begin{array}{l}\sim 25 \mathrm{~m}^{\mathrm{a}} \\
\sim 50 \mathrm{~m}^{\mathrm{a}} \\
100-200 \mathrm{~m}^{\mathrm{b}} \\
\text { few tens of meters-100 } \mathrm{m}^{\mathrm{c}}\end{array}$ \\
\hline Oceanic sections & $\begin{array}{l}\text { 504B data } \\
\text { Hess Deep } \\
\text { Vema Scarp } \\
\text { Blanco Scarp }\end{array}$ & $\begin{array}{l}\text { intermediate } \\
\text { fast } \\
\text { slow } \\
\text { intermediate }\end{array}$ & $\begin{array}{l}575 \mathrm{~m}^{\mathrm{e}} \\
\text { Alvin: }<200-800 \mathrm{~m}^{\mathrm{f}} \\
\text { Nautile: } 100-200 \mathrm{~m}^{\mathrm{g}} \\
280-420 \mathrm{~m}^{\mathrm{h}} \\
475 \mathrm{~m}^{\mathrm{i}}\end{array}$ & $\begin{array}{l}150-200 \mathrm{~m}^{\mathrm{e}} \\
50-500 \mathrm{~m}^{\mathrm{g}}\end{array}$ \\
\hline
\end{tabular}

${ }^{\mathrm{a}}$ Kidd [47]. ${ }^{\mathrm{b}}$ Kidd [1]. ${ }^{\mathrm{c}}$ Lippard et al. [48]. ${ }^{\mathrm{d}}$ Nicolas [42], p. 61. ${ }^{\mathrm{e}}$ Anderson [16]. ${ }^{\mathrm{f}}$ Karson et al. [43] and pers. commun., 1994.

${ }^{g}$ Francheteau et al. [44]. ${ }^{\text {h }}$ Cannat et al. [45]. ${ }^{\text {i }}$ Naidoo et al. [34]. 
in expanding spread profiles [20] at $9^{\circ} 35^{\prime} \mathrm{N}$, and in on-bottom refraction studies [27] at $9^{\circ} 30^{\prime} \mathrm{N}$. Table 1 shows the on-axis and off-axis thicknesses and the width of the $2 \mathrm{~A}$ accretion zone - the distance from the axis over which layer $2 \mathrm{~A}$ thickens to the mean off-axis thickness - for different seismic experiments on the northern and southern EPR. Moving off the rise crest, layer $2 \mathrm{~A}$ is observed to approximately double in thickness over a distance of a few kilometers. In general, on-axis layer $2 \mathrm{~A}$ thicknesses are remarkably uniform, $\sim 230 \pm 50 \mathrm{~m}$ except near overlapping spreading centers where the thicknesses reach $\sim 400 \mathrm{~m}[28,29,41]$. Off-axis thicknesses of $400-800 \mathrm{~m}$ are reached within $1-3 \mathrm{~km}$ of the rise axis. In spite of the differences in spreading rate, layer 2A thicknesses are similar along the northern $(55 \mathrm{~mm} / \mathrm{yr}$ half-rate) and southern $(75 \mathrm{~mm} / \mathrm{yr}$ halfrate) EPR, although different seismic techniques give somewhat different results, due to the differences in inherent resolution [26]. If the velocities in the extrusives and dikes are assumed to be constant and the steep velocity gradient at the base of layer $2 \mathrm{~A}$ is due to the interfingering of these two units, then the thickness of the high velocity gradient zone corresponds to the thickness of the transition zone from extrusives to sheeted dikes. In seismic data from the northern EPR this high velocity gradient zone has a thickness of $\sim 100-300 \mathrm{~m}[20,26]$.

These seismically derived constraints on extrusive layer thickness and thickness of the extrusive-dike transition can be compared with geological observations on sections of oceanic crust exposed in Hess Deep, in ophiolites, and drilled in Hole 504B (Table 2). Extrusive layer thicknesses estimated in ophiolites range from 400 to $1600 \mathrm{~m}[1,42]$. In contrast, estimates of extrusive thicknesses from oceanic scarps are only $\sim 300-500 \mathrm{~m}$ [43-46] while at DSDP Hole 504B the extrusive section is less than $600 \mathrm{~m}$ thick [16], comparable to layer 2A thicknesses determined from off-axis seismic data (Table 1). The extrusive-dike transition zone (defined as the vertical depth from $20 \%$ to $70 \%$ sheeted dikes) is quite thin in ophiolite sections (Table 2), a few tens of meters to $100-200 \mathrm{~m}[1,47,48]$. Oceanic scarps give values also ranging from a few tens of meters up to a few hundred meters [44-46], while at DSDP Hole 504B the extrusive-dike transition is $\sim 150 \mathrm{~m}$ thick [16]. These estimates are comparable to the thickness of the layer $2 \mathrm{~A} / 2 \mathrm{~B}$ transition estimated seismically. Modeling of the extrusive-dike transition thickness in ophiolites shows that the dike intrusion zone must be very narrow, only $10-50 \mathrm{~m}$ wide [1]. Such a narrow dike intrusion width is supported by independent statistical observations of the proportion of dikes in ophiolites that exhibit one-sided cooling, due to having been split by a subsequent dike $[1,17,18]$. Studies of marine magnetic anomaly reversal widths and variability [4-8] suggest a relatively wide zone of lava emplacement, 1-3 km wide. However, these data can not resolve the relative contributions of the width of the intrusion zone and lava flow distribution to the lava emplacement process. Macdonald [6] attributes the width of the magnetic anomaly reversal to a combination of a relatively wide intrusion zone and long lava flows.

There are four observables which help constrain the dimensions of the upper crustal emplacement process: the on-axis $2 \mathrm{~A}$ thickness, off-axis $2 \mathrm{~A}$ thickness, width of the $2 \mathrm{~A}$ accretion zone, and the extrusive-sheeted dike transition thickness. These values are obtained from seismic and geological observations. In this paper we attempt to match two endmember profiles of layer $2 \mathrm{~A}$ thickening from the southern EPR. At the same time we maintain an extrusive-dike transition thickness that is consistent with geological observations - greater than $50 \mathrm{~m}$ and no wider than 150-200 $\mathrm{m}$. The two across-axis seismic sections from the Southern East Pacific Rise, SEPR $31,17^{\circ} 14^{\prime} \mathrm{S}$, and SEPR06, $18^{\circ} 28^{\prime} \mathrm{S}$, (Fig. 1a,c) were chosen because they characterize the variability in the width and shape of thickening of layer $2 \mathrm{~A}$. Although both of these profiles (Fig. 1b,d) have similar on-axis $(250 \mathrm{~m})$ and off-axis layer $2 \mathrm{~A}$ thicknesses $(550 \mathrm{~m})$, they differ in the width of the zone over which the thickening takes place; SEPR31 is narrow (width of the $2 \mathrm{~A}$ accretion zone is $1.2 \mathrm{~km}$ ) while SEPR06 thickens over a wide zone (width of the $2 \mathrm{~A}$ accretion zone is $3 \mathrm{~km}$ ). Both thickening profiles are flat-topped (i.e., the minimum on-axis thickness is maintained for some distance before the layer starts to thicken). 


\section{Emplacement models}

\subsection{Unimodal lava emplacement model}

We use a stochastic model to construct the sheeted dike and extrusive sections of the oceanic crust (c.f. $[4,5])$. At an active spreading center, steady state is only achieved statistically, since the accretion process is a series of discrete, successive events. Fig. 2 shows a schematic example of four steps in the emplacement process. Dikes are injected into the crust at a location determined randomly from a probability function. Each dike is associated with a lava flow. Lava flows out on either side of the locus of intrusion to a distance determined randomly from a second probability function. Earlier flows are covered by later flows. The lava pile subsides as it is covered so that a flat seafloor is maintained. The variables used in the emplacement models are defined in Table 3. The dikes are assumed to have a thickness, $w=1 \mathrm{~m}$. This is consistent with dike widths of 0.5-1.5 m observed at Hess Deep [43] and a mean of $\sim 1 \mathrm{~m}$ for the dike width distribution measured in the Troodos ophiolite, Cyprus [1]. The source region of the dikes lies below the base of our model. The probability function of the location of dike intrusion relative to the ridge axis that we use is a Gaussian, with a standard deviation of intrusion, $\sigma_{i}$. Of the dikes, $95 \%$ are intruded within a distance of $\pm 2 \sigma_{i}$ from the ridge axis. Lava flow lengths are such that cumulative flows erupted at the same location build a Gaussian-shaped extrusive pile with
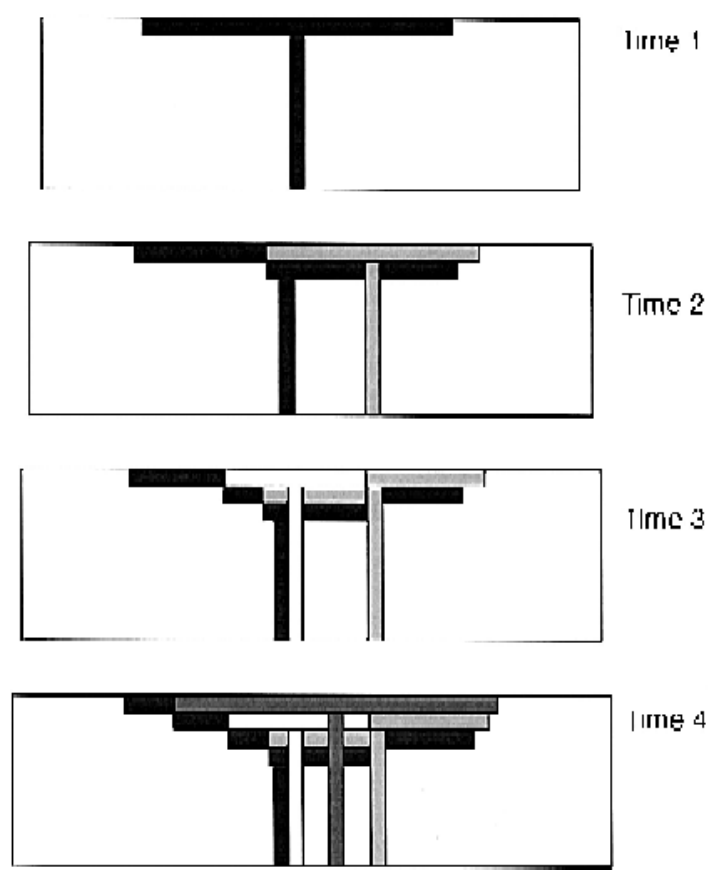

Fig. 2. Cartoon of four steps in the stochastic emplacement process that constructs the upper crust. The location of dike intrusion is determined from the probability function for the intrusion location relative to the ridge axis. Pre-existing crust spreads to the side a distance equal to half a dike width. The length of the lava flow erupted from this dike is determined from the probability function describing the flow lengths. The lava flow extends equal distances on either side of the point of intrusion. Pre-existing crust underlying the new flow subsides an amount equal to one flow thickness. The cycle then repeats itself with the selection of a new point of intrusion and the determination of the accompanying lava flow length.

Table 3

Model variables

\begin{tabular}{|c|c|}
\hline Model variable & Definition \\
\hline \multicolumn{2}{|c|}{ Unimodal Lava Emplacement Model } \\
\hline$\sigma_{i}$ & standard deviation of dike intrusion \\
\hline$\sigma_{e}$ & standard deviation of lava emplacement \\
\hline psO & probability that a dike erupts to form a lava flow \\
\hline$t$ & thickness of the lava flows \\
\hline$w$ & width of the dikes $=1 \mathrm{~m}$ \\
\hline \multicolumn{2}{|c|}{ Bimodal Lava Emplacement Model } \\
\hline$\sigma_{i}$ & standard deviation of dike intrusion for all flows $=10 \mathrm{~m}$ \\
\hline$\sigma_{e S}$ & standard deviation of lava emplacement of the short flows ( $95 \%$ of events) \\
\hline$\sigma_{e L}$ & standard deviation of lava emplacement of the long flows (5\% of events) \\
\hline $\operatorname{minl}$ & distance over which no lava accumulates for the long flows \\
\hline$t$ & thickness of the lava flows (both short and long) \\
\hline psO & probability that a dike erupts to form a lava flow $=1$ \\
\hline$w$ & width of the dikes $=1 \mathrm{~m}$ \\
\hline
\end{tabular}


standard deviation $\sigma_{e}$. Thus, the half-flow length probability function that we chose is the derivative of a half-Gaussian, which is the Rayleigh distribution. The flows have a uniform thickness, $t$, and the median flow length is $(2 \pi)^{1 / 2} \sigma_{e}$. Observations in Hawaii and Iceland suggest that a significant proportion $(50-75 \%)$ of diking events do not form a surface eruption (Delaney, pers. commun., RIDGE The-

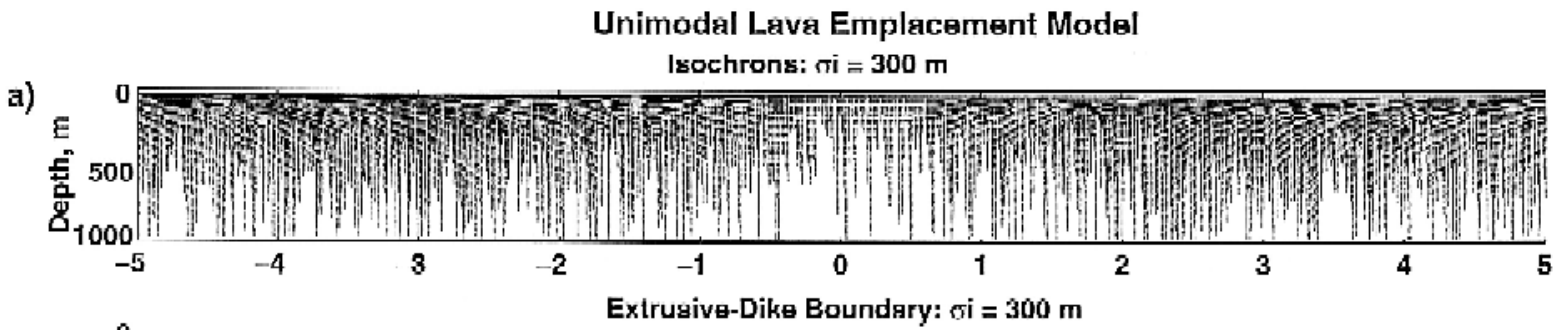

b)

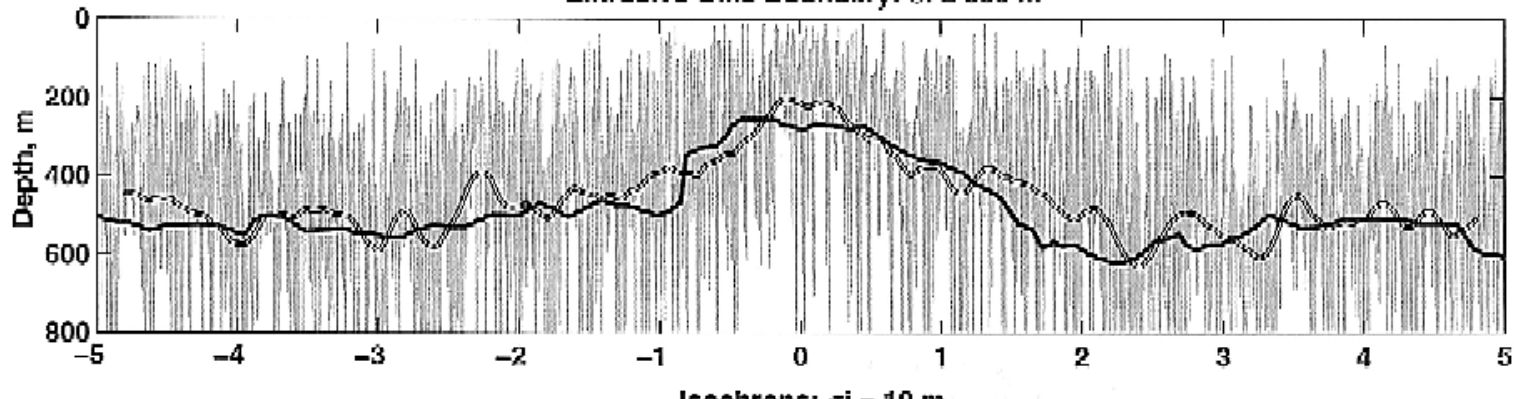

c)

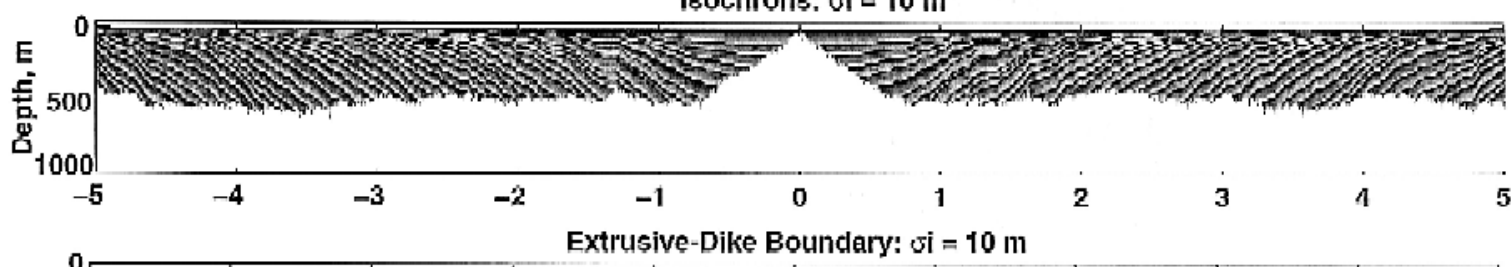

d)

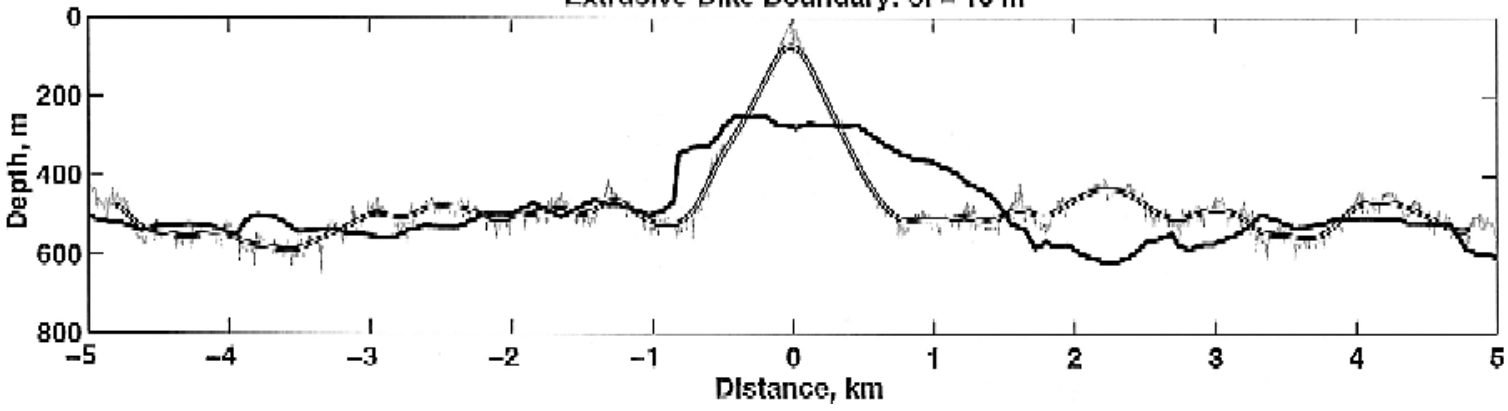

Fig. 3. Two runs of the unimodal lava emplacement model of upper crustal construction where the standard deviation of intrusion is wide, $\sigma_{i}=300 \mathrm{~m}(\mathrm{a}$ and $\mathrm{b})$ and narrow, $\sigma_{i}=10 \mathrm{~m}$ (c and d), the standard deviation of extrusion, $\sigma_{e}=500 \mathrm{~m}$, the thickness of the dikes and of the lava flows is $1 \mathrm{~m}$ and $40 \%$ of the dikes erupt a lava flow. (a) and (c) The isochrons within the extrusives are shown by changing shades of gray. The dikes are shown in white. No vertical exaggeration. (b) and (d) The gray line is the boundary between the sheeted dikes and extrusives. The hollow line is the result of spatially filtering the extrusive-dike boundary with a triangular filter of wavelength $200 \mathrm{~m}$ to simulate a seismic observation of this contact. The solid black line is the across-axis layer 2A thickness from line SEPR31. For the model with $\sigma_{i}=300 \mathrm{~m}$ the character as well as the on-axis $(200 \mathrm{~m})$, off-axis thicknesses $(510 \mathrm{~m})$, and width of the $2 \mathrm{~A}$ accretion zone $(2300 \mathrm{~m})$ match the seismic profile well. However, the transition zone from extrusives to sheeted dikes is $310 \mathrm{~m}$, thicker than that observed in ophiolite sections and oceanic scarps. When $\sigma_{i}=10 \mathrm{~m}$, the transition zone from extrusives to sheeted dikes is $50 \mathrm{~m}$, comparable to ophiolite and oceanic scarp observations. However, the shape of the layer $2 \mathrm{~A}$ boundary is pointed rather than flat-topped, with a very small on-axis thickness $(70 \mathrm{~m})$ and does not resemble the seismic profile. 
oretical Institute, June, 1995). This results in additional extension during lava emplacement or, alternatively, represents a change in the effective ratio of the thickness of the dikes to that of the lava flows. We incorporate this effect by introducing the variable $p s 0$, which represents the probability that a dike will actually erupt to form a lava flow on the seafloor. Any extension of the crust due to tectonics is considered negligible in this model. At fast spreading ridges faulting accounts for only $3-10 \%$ of the total spreading rate $[49,50]$. To match a full spreading rate of $150 \mathrm{~mm} / \mathrm{yr}$ (southern EPR) a $1 \mathrm{~m}$ thick dike must be intruded on average every 7 years, assuming that all the extension is accommodated by construction of the sheeted dike section. At a full spreading rate of $110 \mathrm{~mm} / \mathrm{yr}$ (northern EPR) a diking event occurs on average every 9 years. Note, however, that diking events are likely to be clustered in time at any particular location with intervening quiescent periods.
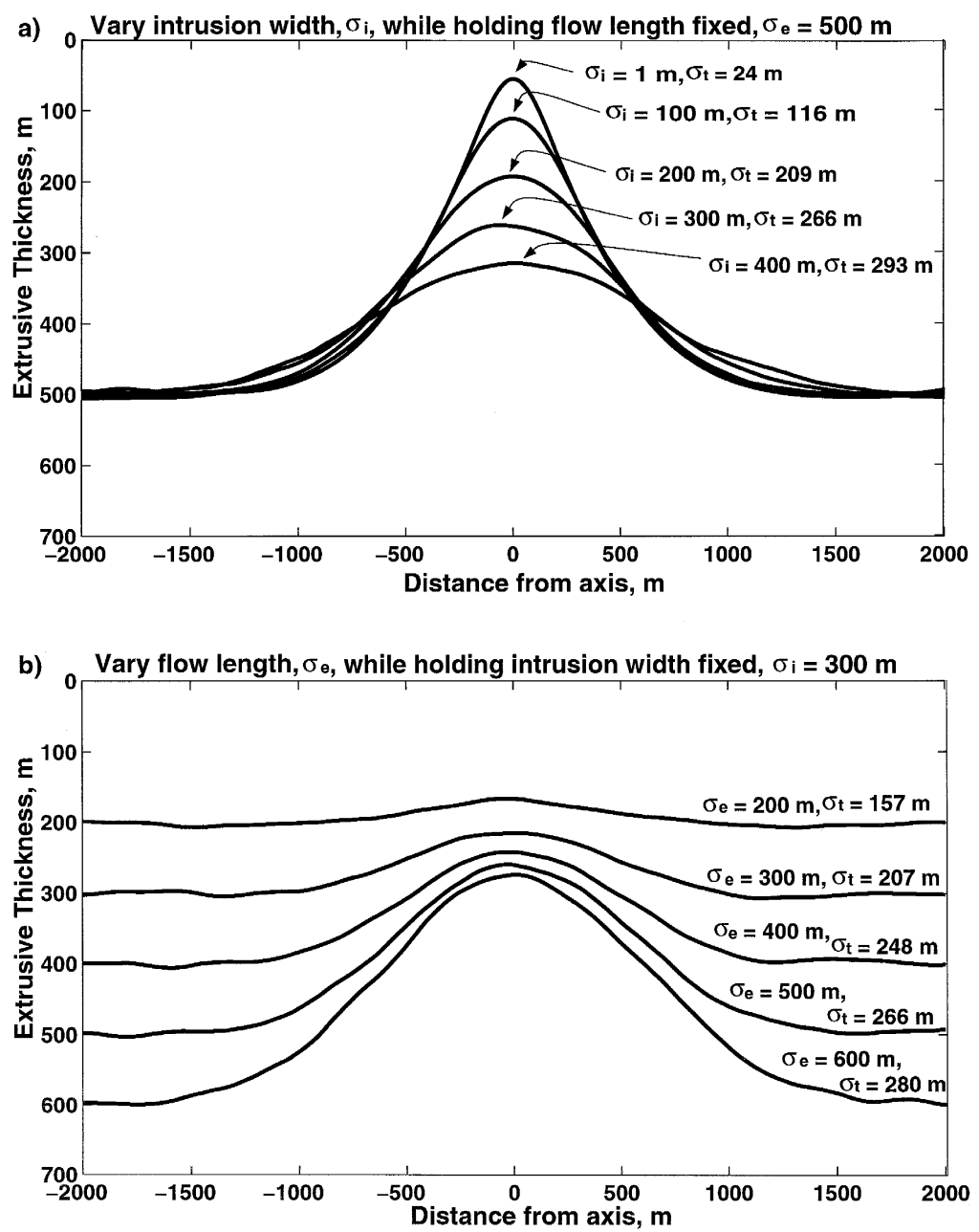

Fig. 4. The change in shape of the $2 \mathrm{~A} / 2 \mathrm{~B}$ boundary when varying the standard deviation of dike intrusion $\sigma_{i}$, and the standard deviation of lava emplacement, $\sigma_{e}$, for the unimodal lava emplacement model. The curves shown are for averages of 50 model runs which are subsequently filtered with a triangular filter of $200 \mathrm{~m}$ wavelength. For these runs, $p s 0=0.4, t=1 \mathrm{~m}$, and $w=1 \mathrm{~m}$. (a) The intrusion width is varied, $\sigma_{i}=1-400 \mathrm{~m}$ in $100 \mathrm{~m}$ increments, while the flow length is held fixed, $\sigma_{e}=500 \mathrm{~m}$. (b) The flow length is varied, $\sigma_{e}=200-600$ in $100 \mathrm{~m}$ increments, while the intrusion width remains fixed, $\sigma_{i}=300 \mathrm{~m}$. The standard deviation of the mean of the 50 model runs, $\sigma_{t}$, is indicated as a measure of the variability in the profiles, which reflects the thickness of the transition zone from $20 \%$ to $70 \%$ sheeted dikes. 
The crustal structure generated by our model generates a highly variable contact between the extrusives and sheeted dikes and predicts that isochrons within the extrusive section dip towards the ridge axis (Fig. 3a). Fig. 3a shows the result of over 10,000 intrusion and emplacement events to form an upper crustal section $10 \mathrm{~km}$ wide. To match seismic profile SEPR31, the model was run using $\sigma_{i}=300$ $\mathrm{m}$, and $\sigma_{e}=500 \mathrm{~m}$, with $40 \%$ of the dikes erupting. On average, as they are rafted away from the axis, the tips of the earlier flows are not covered by subsequent flows, resulting in isochrons within the upper crustal section which dip towards the ridge axis. The contact between sheeted dikes and extrusives in this model is extremely variable. To simulate a seismic observation of the extrusive-sheeted dike contact that is generated by this model, we have smoothed the contact using a triangular filter with a width of one seismic wavelength (Fig. 3b). At a dominant frequency of $20 \mathrm{~Hz}$ and crustal velocity of $\sim 4 \mathrm{~km} / \mathrm{s}$, the seismic wavelength is $200 \mathrm{~m}$. One seismic wavelength is an approximation of the distance required for the energy to turn within layer $2 \mathrm{~A}$ and generate a wide-angle 'reflection'/refraction. The variation in extrusive layer thickness predicted by the model compares well with seismic observations of layer $2 \mathrm{~A}$ thickness variations at the EPR in terms of the on-axis $(200 \mathrm{~m})$ and off-axis $(510 \mathrm{~m})$ thicknesses and the distance over which this thickening occurs (2300 m half-width). However, the extrusive-dike transition thickness calculated from the model is $310 \mathrm{~m}$, wider than most geological estimates (Table 2). If the model is run with the same $\sigma_{e}$ but $\sigma_{i}=10 \mathrm{~m}$ (Fig. $3 \mathrm{c}, \mathrm{d}$ ), the transition zone from extrusives to sheeted dikes is $50 \mathrm{~m}$, which is comparable to ophiolite and oceanic scarp observations. However, now the shape of the layer 2A boundary is pointed rather than flat-topped with a very small on-axis thickness $(70 \mathrm{~m})$, which does not resemble the seismic profile. When the extrusive-dike transition thickness is included as a constraint, there is no longer a solution of the unimodal lava emplacement model which satisfies the four seismic and geological observables.

\subsection{Sensitivity of the model}

We examine the effect of changing the character- istic dimensions of dike intrusion and lava emplacement on the four observables that we can measure: the on-axis extrusive layer thickness, the off-axis extrusive layer thickness, the width of $2 A$ accretion and the transition thickness from $20 \%$ to $70 \%$ sheeted dikes. The unimodal lava emplacement model is characterized by five parameters (Table 3): the standard deviation of dike intrusion, $\sigma_{i}$, the standard deviation of the extrusive pile, $\sigma_{e}$, the probability that a dike will erupt a lava flow, $p s 0$, the thickness of the lava flows, $t$, and the width of the dikes, $w$. Fig. 4 shows the effect of varying the two parameters, $\sigma_{i}$ and $\sigma_{e}$, on the shape of the $2 \mathrm{~A} / 2 \mathrm{~B}$ boundary for an average of 50 model runs which are subsequently filtered with a $200 \mathrm{~m}$ wavelength triangular filter. For these runs, $p s 0=0.4, t=1 \mathrm{~m}$, and $w=1$ $\mathrm{m}$. The parameter $\sigma_{t}$ is the standard deviation of the mean of the 50 model runs and reflects the thickness of the transition zone from $20-70 \%$ sheeted dikes. In Fig. $4 \mathrm{a}, \sigma_{e}$ is held fixed. If $\sigma_{i}$ is extremely narrow, then the $2 \mathrm{~A} / 2 \mathrm{~B}$ boundary will have a pointed shape with a very thin layer $2 \mathrm{~A}$ at the rise axis and a very narrow transition thickness, $\sigma_{t}$ (Fig. 3c,d). If $\sigma_{i}$ is wider, then the on-axis thickness of layer $2 \mathrm{~A}$ and the thickness of the transition zone increase, and the 2A/2B boundary has a broader, flat-topped shape. The off-axis thickness remains constant, since $\sigma_{e}$ is constant, and thus, when the statistical variability of the model is smoothed out, the total volume of extrusives remains the same. In Fig. $4 \mathrm{~b}, \sigma_{i}$ is held constant and $\sigma_{e}$ is increased. This results in an increase in the off-axis thickness of the extrusive layer, which is accompanied by an increase in on-axis thickness. Longer flows also result in layer 2A thickening over a greater distance off-axis and lead to a small increase in the thickness of the transition zone, $\sigma_{t}$.

The off-axis thickness of the lava pile can be determined from mass conservation and is independent of $\sigma_{i}$. The off-axis extrusive thickness is:

$(2 \pi)^{1 / 2} \sigma_{e}\left(\frac{t \cdot p s 0)}{w}\right)$

The off-axis extrusive thickness depends on the mean lava flow length, scales linearly with the flow thickness and with the percentage of dikes that erupt, and scales inversely with dike width. Fig. 5a shows 
a)

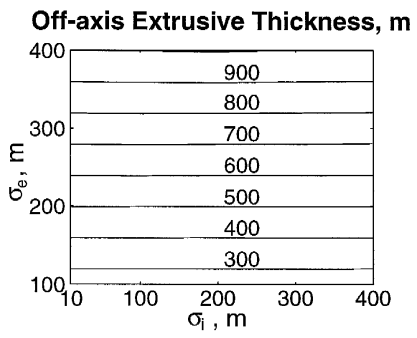

b)

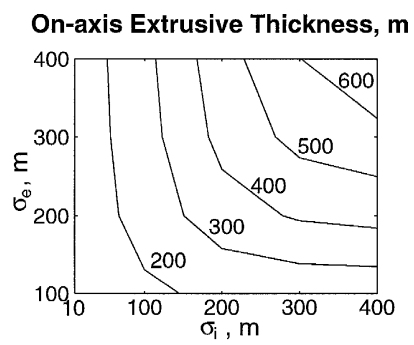

c)

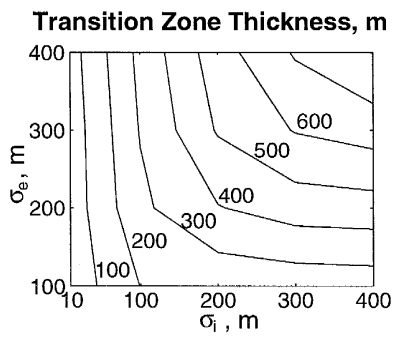

Fig. 5. Contour plots of the values of the on-axis extrusive thickness, off-axis extrusive thickness, and transition thickness as a function of $\sigma_{i}$ and $\sigma_{e}$ for the unimodal lava emplacement model. Values are determined from the mean of five runs of the emplacement model with $\sigma_{i}$ ranging from 10 to $400 \mathrm{~m}$ and $\sigma_{e}$ ranging from 100 to $400 \mathrm{~m}$. For these iterations the scaling variables are held fixed; $t=1 \mathrm{~m}, w=1 \mathrm{~m}$, and $p s 0=1$. The on-axis thickness of the extrusive layer and the extrusive-dike transition thickness are sensitive to both $\sigma_{i}$ and $\sigma_{e}$, while the off-axis extrusive layer thickness depends only on $\sigma_{e}$.

the off-axis extrusive thickness as a function of the two stochastic variables, $\sigma_{i}$ and $\sigma_{e}$, determined from the mean of five runs of the emplacement model, with $\sigma_{i}$ ranging from 10 to $400 \mathrm{~m}$ and $\sigma_{e}$ ranging from 100 to $400 \mathrm{~m}$. The on-axis extrusive thickness depends on the ratio of the two standard deviations and scales in the same way as the off-axis extrusive thickness:

$$
(2 \pi)^{1 / 2} \sigma_{e}\left[1-\exp \left(\frac{-\sigma_{i}}{\sigma_{e}}\right)\right]\left(\frac{t \cdot p s 0}{w}\right)
$$

The on-axis extrusive thickness is contoured as a function of $\sigma_{i}$ and $\sigma_{e}$ in Fig. 5b. As the intrusive width and the flow length tend to zero, the on-axis thickness goes to zero. For an infinitely wide intrusion zone, the extrusive thickness on axis is equal to that off axis. The thickness of the transition zone from extrusives to sheeted dikes is shown in Fig. 5c and has a similar dependence on $\sigma_{i}, \sigma_{e}, t, p s O$ and $w$ as the on-axis extrusive thickness. Note that, for the definition that we have chosen $(20-70 \%$ sheeted dikes), the transition width is always greater than or equal to the on-axis extrusive thickness. The width of the $2 \mathrm{~A}$ accretion zone is a less stable measurement and much more sensitive to the statistical variability in the model. As can be seen from Fig. 4, the width of the $2 \mathrm{~A}$ accretion zone is positively related to $\sigma_{e}$ but also varies with $\sigma_{i}$. The width of the $2 \mathrm{~A}$ accretion zone is independent of $t$, but depends on psO and $w$.

This stochastic emplacement model with a unimodal distribution of flows matches the variation in layer 2A thickness observed seismically at the EPR (Fig. 3) and provides some intuitive insight into the processes that control extrusive thickness at fast spreading ridges. For example, this model shows that the distance off-axis at which layer $2 \mathrm{~A}$ reaches its final thickness is primarily affected by the distance flows extend off-axis. For a unimodal distribution of flows, the shape of the layer 2A/2B boundary (flattopped rather than triangular) requires a zone of intrusion on the order of a few hundred meters. However, this unimodal lava emplacement model cannot explain both the broad, flat-topped shape of the layer $2 \mathrm{~A} / 2 \mathrm{~B}$ boundary and at the same time the sharpness of the extrusive-dike transition measured in outcrop and drill holes. The wider intrusion zone required to match the seismic observations will result in a broad transition zone, due to the variability in location of dike intrusion. Indeed, for this unimodal lava emplacement model the transition thickness is greater than or equal to the on-axis layer $2 \mathrm{~A}$ thickness, which at the EPR is about $250 \mathrm{~m}$ (Fig. 5). The transition thickness predicted for the model shown in Fig. 3, which fits the observed layer 2A thickness, is over $300 \mathrm{~m}$. This is larger than transition thicknesses 
of a few tens of meters to $100-200 \mathrm{~m}$ measured in ophiolites [1,42] and $150-200 \mathrm{~m}$ drilled at Hole 504B [16] (Table 2). To match the observed sharpness of the extrusive-dike transition thickness, the standard deviation of intrusion must be narrower than the mean flow length by about an order of magnitude [1]. Solutions to the unimodal lava emplacement model which match the shape of the seismic $2 \mathrm{~A} / 2 \mathrm{~B}$ boundary have $\sigma_{i}$ and $\sigma_{e}$ of the same order of magnitude. In order to match the sharpness of the extrusive-dike transition zone observed in ophiolites, $\sigma_{i}$ must be of the order of $10-50 \mathrm{~m}$. However, this will result in a very small on-axis 2A thickness and a boundary which is peaked rather than flat-topped (Fig. 3c,d), contrary to what is observed in the seismic data.

\subsection{Bimodal lava emplacement model}

We propose a stochastic emplacement model with a bimodal distribution of flows in order to match both the dimensions and shape of the seismic boundary and the geologically observed extrusive-dike transition thickness. The idea underlying the bimodal lava emplacement model is to rapidly build up the on-axis thickness of extrusives by accumulating a sequence of short flows erupted at the ridge crest (standard deviation of emplacement, $\sigma_{e S}$ ). The more progressive thickening of the extrusive layer over $1-3 \mathrm{~km}$ observed in the seismic sections is accomplished by a series of flows that are about as long as the width of the region of thickening (standard deviation of emplacement, $\sigma_{e L}$ ). Geologically, the short flows remain confined within the axial summit caldera (ASC). The long flows flow down the flanks of the rise crest, are channelled across the shoulders of the rise in lava tubes, or erupt outside the ASC (Fig. 6). The upper part of the resulting extrusive section is composed of flows deposited away from the axis while the lower portion consists of flows deposited on-axis. Since the on-axis thickness of layer $2 \mathrm{~A}$ is approximately half of the off-axis thickness, the on-axis and off-axis flows must contribute equal volumes to the extrusive section. To accomplish this, if the flows all have the same thickness, the short flows must be erupted much more frequently than the long flows (95\% of the time). In this case, the mean volume of the long flows is $\sim 20$ times that of the short flows. On the other hand, the relative number of events decreases if the short flows are much thicker than the long flows, possibly due to the ponding of these flows against the walls of the ASC. A flow thickness $t=2 \mathrm{~m}$ implies flows with a cross-sectional area of $2,000 \mathrm{~m}^{2}$ for the long flows. To compare this 2-D flow volume with that of the mid-crustal melt sill, we assume a melt sill thickness of $50 \mathrm{~m}$ and a sill width of $800 \mathrm{~m}$ [51]. The melt sill has a volume of $4,000 \mathrm{~m}^{2}$, twice that needed to form the rare, voluminous, long flow length eruptions.

A model to build the extrusive section of the ocean crust that combines an initially narrow and subsequently wide zone of accretion was suggested

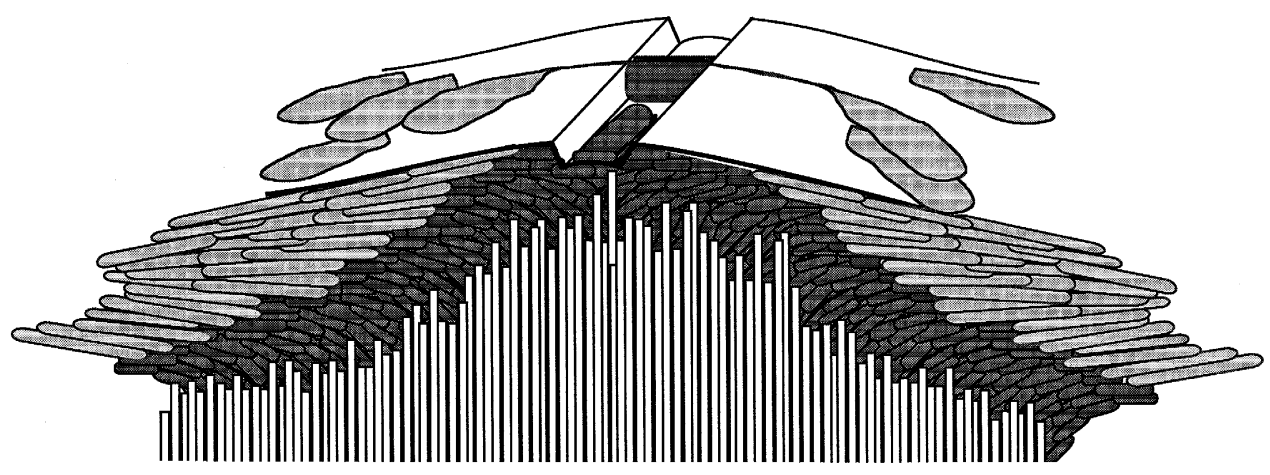

Fig. 6. Diagram showing the bimodal flow length emplacement model. Short flows, shown in dark gray, remain confined within the axial summit caldera (ASC) and build up half the volume of the extrusive section. Occasional long flows, shown in light gray, are envisioned to flow down the flanks of the rise crest, be channeled across the shoulders of the rise in lava tubes, or erupt outside the ASC. They flow far off-axis and build up the remainder of the extrusive section. The accompanying dikes are shown in white. 


\section{Bimodal Lava Emplacement Model}

a)

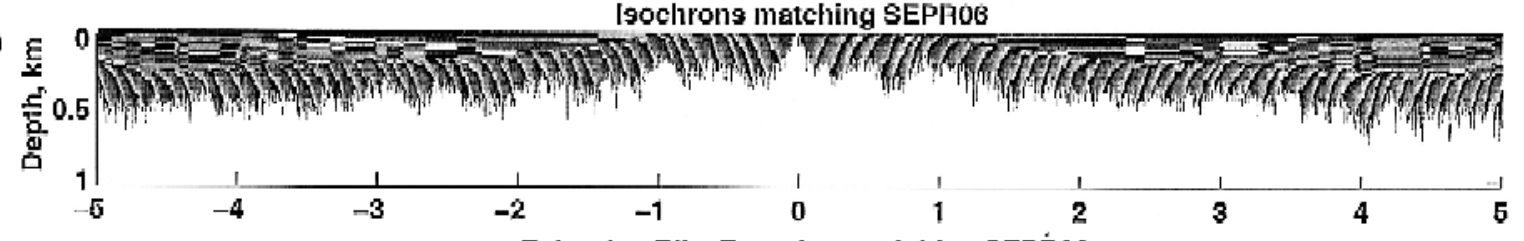

b)

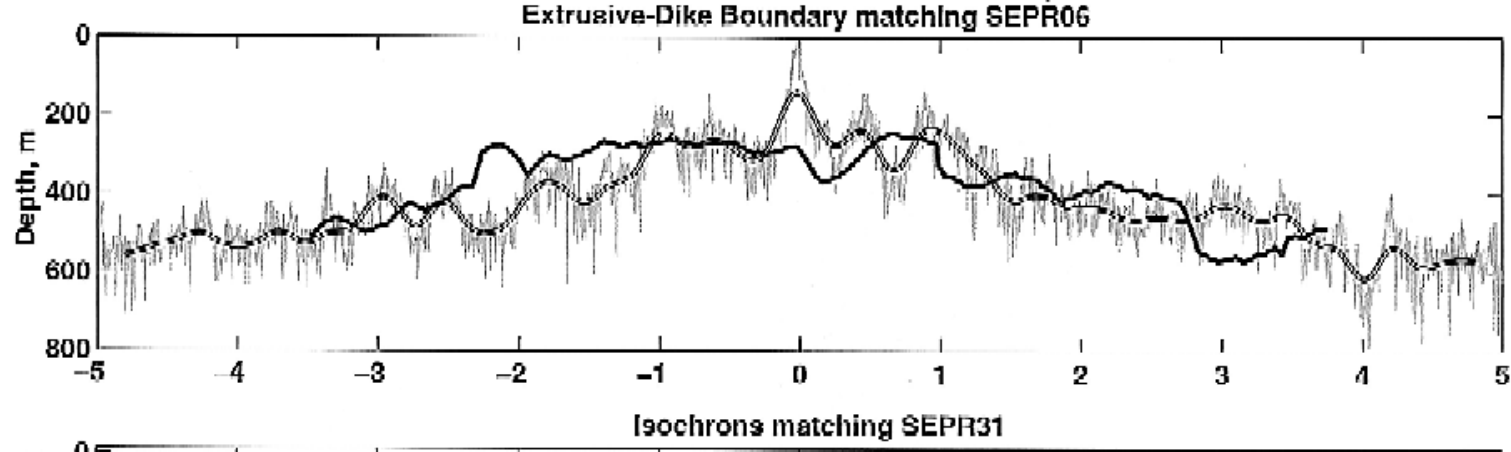

c)

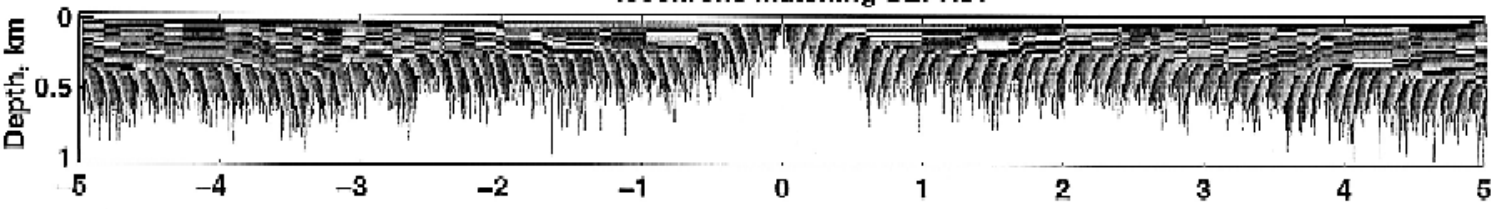

d)

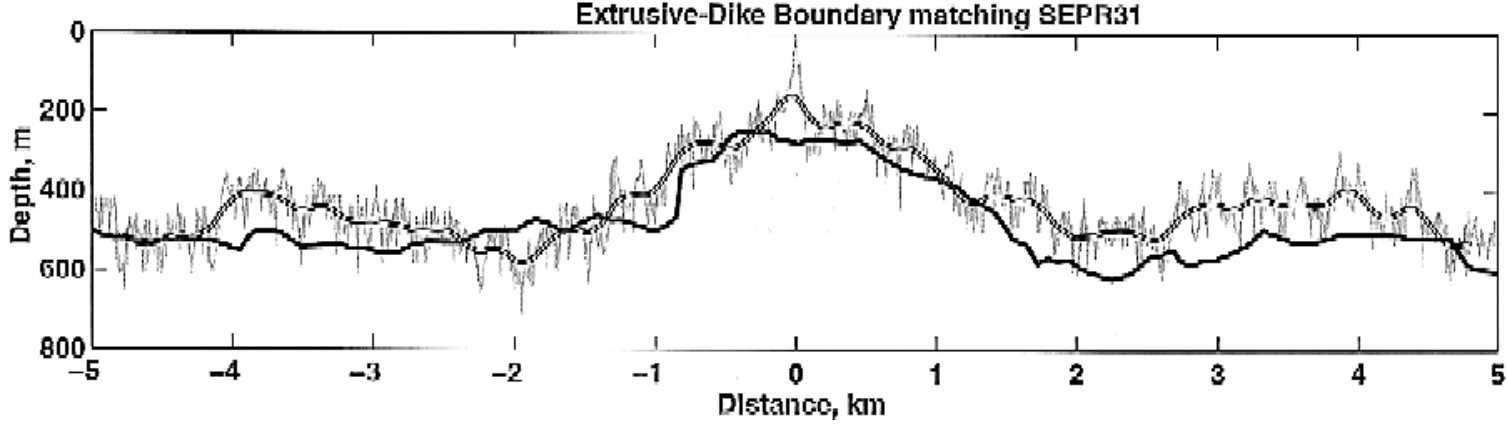

Fig. 7. Two examples of runs of the bimodal lava emplacement model of upper crustal construction that match the layer $2 \mathrm{~A}$ thicknesses for the across-axis seismic lines SEPR06 (wide region of 2A accretion) and SEPR31 (narrow region of 2A accretion) shown in Fig. 1. (a) Run of the bimodal lava emplacement model that matches SEPR06; standard deviation of intrusion, $\sigma_{i}=10 \mathrm{~m}$, lava flow distribution, $95 \%$ of the flows have $\sigma_{e S}=75 \mathrm{~m}, 5 \%$ of the flows have $\sigma_{e L}=1500 \mathrm{~m}, t=1.5 \mathrm{~m}$. For the long flows the distance over which no lava accumulates is $1000 \mathrm{~m}$. (c) Run of the bimodal lava emplacement model that matches SEPR31; standard deviation of intrusion, $\sigma_{i}=10 \mathrm{~m}$, lava flow distribution, $95 \%$ of the flows have $\sigma_{e S}=50 \mathrm{~m}, 5 \%$ of the flows have $\sigma_{e L}=1000 \mathrm{~m}, t=2.2 \mathrm{~m}$. For the long flows the distance over which no lava accumulates is $400 \mathrm{~m}$. In both figures the isochrons in the extrusive section are shown with a gray scale, sheeted dikes are in white. No vertical exaggeration. Note the shallow dip of the upper extrusive section $\left(0-10^{\circ}\right.$ and $\left.15^{\circ}\right)$ and the steep dips in the lower extrusives, $50-70^{\circ}$. The boundary between the two units is sharp and dips are zero at the contact. (b) and (d) The gray line is the boundary between the sheeted dikes and extrusives for the two model runs. The hollow line shows the model extrusive-sheeted dike contact averaged using a 200 $\mathrm{m}$ wavelength triangular filter. The black line is the layer 2A thicknesses determined from (b) line SEPR06 and (d) line SEPR31. The on-axis, off-axis thicknesses and the widths of the $2 \mathrm{~A}$ accretion zone match well. The transition zone thickness for these models is $90 \mathrm{~m}$ and $70 \mathrm{~m}$, respectively, compatible with measurements made on ophiolites and oceanic crustal scarps. Note that these fits are not unique, but provide a characterization of the differences and types of length scales required to fit the observables available to constrain crustal accretion. 
by Atwater [52] to reconcile: (a) the observation of a wide emplacement zone suggested by the presence of intact volcanoes on the surface of the off-axis seafloor in the FAMOUS area; and (b) ophiolite observations of a very localized transition from extrusives to sheeted dikes. Our attempt to constrain the accretion process using the geometry and dimensions of the seismic layer $2 \mathrm{~A}$ boundary and, at the same time, match the transition thickness observed in ophiolites has also led us to require a bimodal lava emplacement model for the fast spreading EPR. Our ability to image seismically layer $2 \mathrm{~A}$ thickness variations enables us to constrain the relative volumes contributed by these two modes of extrusion and the length scales involved.

In the bimodal lava emplacement model, the narrow intrusion zone and short flows generate the on-axis extrusive pile and result in a narrow transition zone from extrusives to sheeted dikes. The off-axis flows thicken the crust to the final thickness over the distance of a few kilometers. However, the shape of the extrusive-sheeted dike boundary obtained remains pointed rather than flat-topped. To obtain a flat-topped $2 \mathrm{~A} / 2 \mathrm{~B}$ boundary, as is observed in the across-axis seismic lines (Fig. 1), zero eruptive volume from the long flows must be accumulated over the flat region. A distribution of long flows that have zero thickness until some distance, minl, from the axis (Fig. 2c) gives an inflection point in the cumulative lava volume. This simulates eruptions that flow over the shoulders of the ASC, leaving a negligible thickness of lava until they pond in deeper areas off-axis. Alternatively, this represents flows that are channelled, perhaps in subseafloor lava tubes, from the axis across the rift shoulders to an eruption site off-axis [14], or voluminous flows that are erupted off-axis from a small number of dikes (Fig. 6). Once a flow leaves the summit region there is little to impede its flow until it reaches the base of the axial high 3-4 km off-axis. The variables used in the bimodal lava emplacement model are listed in Table 3. To keep the number of variables to a minimum, we have kept $\sigma_{i}$ the same for both the long and the short lava flows $\left(\sigma_{i}=10 \mathrm{~m}\right)$ and we fixed $p s O=1$ and $w=1 \mathrm{~m}$. As in the unimodal lava emplacement model, the effect of decreasing the thickness of the lava flows or decreasing the amount of dikes that erupt a lava flow is to decrease the thickness of the extrusive pile and of the transition zone. Decreasing the amount of dikes that erupt a lava flow also broadens the width of the $2 \mathrm{~A}$ accretion zone.

Fig. 7 shows two examples of the bimodal lava emplacement model that match the two across-axis seismic lines which represent extremes of the distance over which the off-axis thickness is attained, SEPR06 (broad 2A accretion zone) and SEPR31 (narrow 2A accretion zone), shown in Fig. 1. Solutions to both the unimodal and the bimodal lava emplacement models are non-unique, but the crustal accretion models that we present provide a characterization of the differences and types of length scales required to match the available observations. To fit layer 2A thicknesses for line SEPR06 (Fig. 7a,b), the model had a standard deviation of intrusion, $\sigma_{i}=10$ $\mathrm{m}$; lava flow length distribution, $95 \%$ of the flows have $\sigma_{e S}=75 \mathrm{~m}, 5 \%$ of the flows have $\sigma_{e L}=1500$ $\mathrm{m}$; and the thickness of the lava flows, $t=1.5 \mathrm{~m}$. As a simplification, we assume that all dikes erupt a lava flow, since there is a trade-off between lava flow thickness and percentage of dikes erupting flows. For the long flows, the distance from the axis over which no off-axis lava accumulates, $\operatorname{minl}=$ $1000 \mathrm{~m}$. This is the distance from the axis over which layer $2 \mathrm{~A}$ is not accreting new material beyond what was built up on the axis (Fig. 1b). Averaging the geological contact obtained from this model with a $200 \mathrm{~m}$ wavelength triangular filter gave model values of on-axis thickness $=140 \mathrm{~m}$, off-axis thickness $=460 \mathrm{~m}$, width of $2 \mathrm{~A}$ accretion zone $=2170 \mathrm{~m}$, and transition zone thickness $=90 \mathrm{~m}$. A good match was also obtained for line SEPR31 (Fig. 7c,d). The model parameters used in this case were: standard deviation of intrusion, $\sigma_{i}=10 \mathrm{~m}$; lava flow length distribution, $95 \%$ of the flows have $\sigma_{e S}=50 \mathrm{~m}, 5 \%$ of the flows have $\sigma_{e L}=1000 \mathrm{~m}$; and the thickness of the lava flows, $t=2.2 \mathrm{~m}$. For the long flows the distance over which no off-axis lava accumulates, $\min l=400 \mathrm{~m}-$ layer $2 \mathrm{~A}$ does not thicken beyond the on-axis thickness over this distance from the ridge axis (Fig. 1d). The filtered sheeted dike-extrusive boundary had an on-axis thickness $=160 \mathrm{~m}$, off-axis thickness $=500 \mathrm{~m}$, width of $2 \mathrm{~A}$ accretion zone $=1700 \mathrm{~m}$ and a transition thickness $=70 \mathrm{~m}$. For these two model runs the filtered extrusive-dike contact matches the seismic layer $2 \mathrm{~A}$ thickness pro- 


\section{A}

a) Binodgl Luve Emplaeement Model Fltered Velocity structura; wavalangth $=200 \mathrm{~m}$

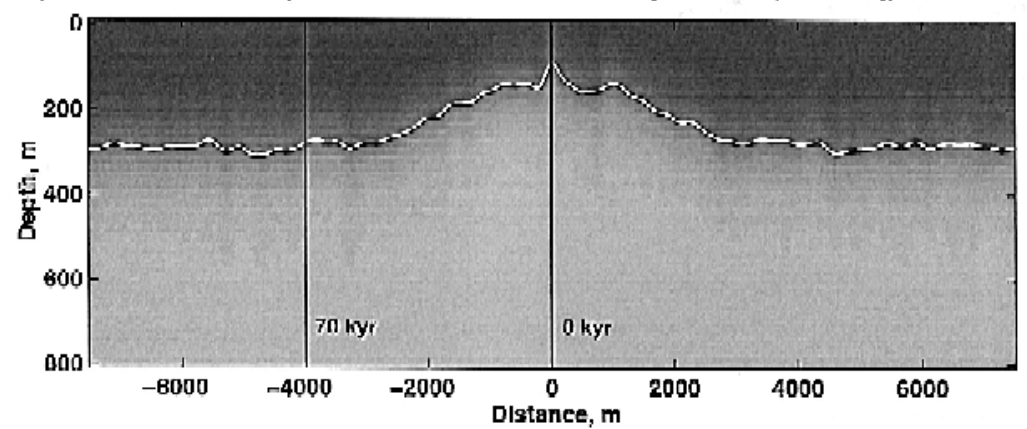

b)

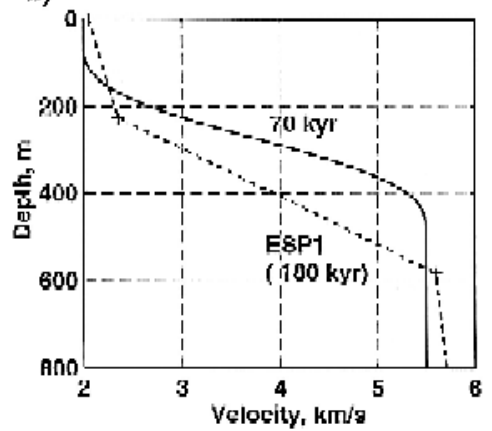

c)

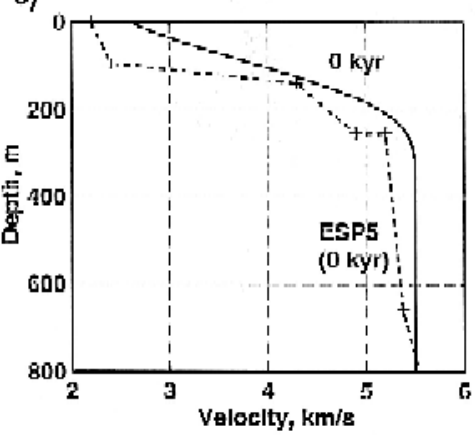

$B$

a) Bimodal Lava Emplacement Modol Filtered Veloclty Strueturs; wavelength = $67 \mathrm{~m}$

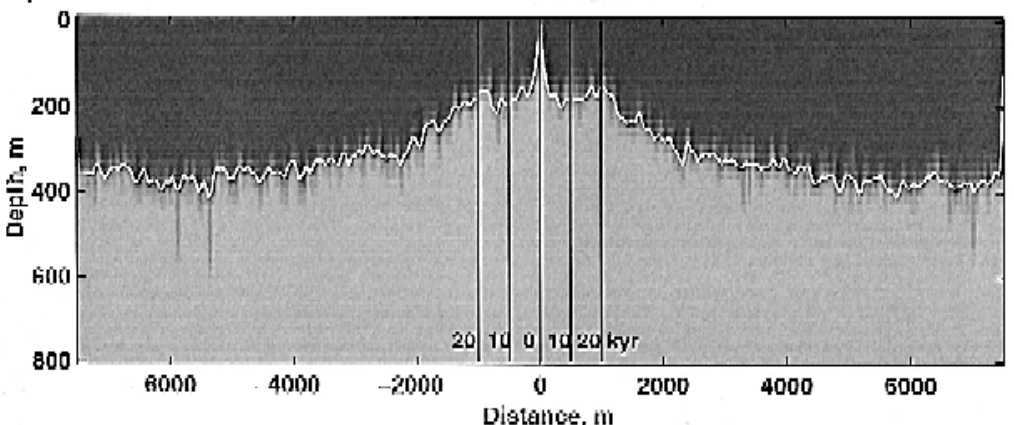

b)

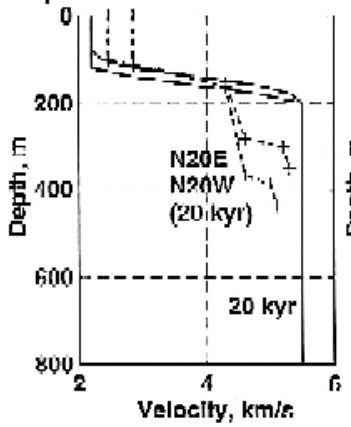

c)

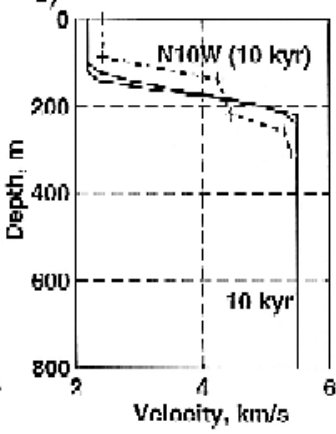

d)

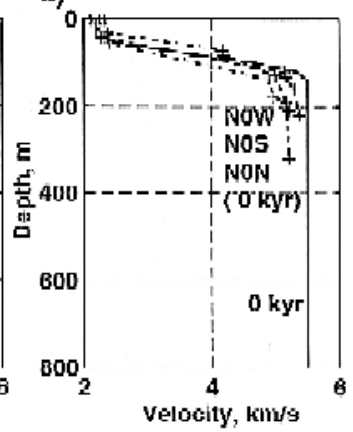


files well, both in terms of its shape, variability, and extrusive thickness values. In addition, the transition thicknesses calculated from the bimodal lava emplacement model are comparable to those measured in ophiolites and oceanic crustal sections. The differences in the width of the zone of $2 \mathrm{~A}$ accretion for the two models is consistent with the observed variation in across-axis topography for the two seismic profiles (Fig. 1a,c). SEPR06 has a broad axial high and thus off-axis lava flows do not pond till further from the ridge axis, resulting in a broader zone of thickening. On the other hand, SEPR31 shows a subdued narrow axial high and thus long lava flows rapidly reach relatively flat seafloor and pond closer to the rise axis, causing earlier thickening of the lava pile and a narrow $2 \mathrm{~A}$ accretion zone.

\section{Implications of the model}

In this section we explore the implications of the stochastic emplacement model for measured seismic velocities in the upper crust, magnetic anomaly transition widths, and seafloor lava ages. From the model we determined the velocity structure of the upper crust, the dip of isochrons with depth, the age of seafloor lavas relative to the underlying crust, and magnetic transition widths. The thickness of the shallow, steep velocity gradient reflects the thickness of the transition region from extrusives to sheeted dikes and the inherent resolution of the seismic technique used. The length of the lava flows and their subsidence rates affect the dip of isochrons in the extrusive section, the width of the transition region observed in magnetic anomalies, as well as the age of lavas on the seafloor.

\subsection{Velocity-depth profiles of the upper crust}

In order to see if the emplacement model that we propose is consistent with the shallow velocity structure observed at the EPR, we have calculated a synthetic velocity structure based on the distribution of extrusives and dikes predicted from the emplacement model. The shallow velocity structure of the crust is primarily determined by bulk porosity. Fractured porous lavas have a higher porosity than massive sheeted dikes so the relative abundance of lavas and dikes in a vertical section will have a major effect on the velocity structure. We assume that the velocities in the extrusive and sheeted dike sections are constant and equal to $2.2 \mathrm{~km} / \mathrm{s}$ and $5.5 \mathrm{~km} / \mathrm{s}$, respectively. The constant low velocity extrusive section results in a surficial low velocity zone. The underlying high gradient region is due to the mixed zone where dikes and extrusives interfinger. This is an approximation which does not take into account the probable variation of velocity with depth within the extrusive pile that results as this layer gets buried and porosity, decreases due to the closing of cracks and voids. Differences due to any morphological or chemical differences between the on-axis and the off-axis flows (i.e. the upper and lower extrusives) are also ignored.

The first area where we compare the measured with the predicted seismic velocity structure is $9^{\circ} 35^{\prime} \mathrm{N}$

Fig. 8. A(a) Velocity structure for a bimodal lava emplacement model run that fits the layer 2A thicknesses measured on the wide aperture profile at $9^{\circ} 35^{\prime} \mathrm{N}$ EPR [24]. $\sigma_{i}=10 \mathrm{~m}, \sigma_{e S}=60 \mathrm{~m}, \sigma_{e L}=1200 \mathrm{~m}, t=1 \mathrm{~m}, \operatorname{minl}=1000 \mathrm{~m}$. Velocities of $2.2 \mathrm{~km} / \mathrm{s}$ (dark gray) and 5.5 $\mathrm{km} / \mathrm{s}$ (light gray) are assigned to the extrusive and sheeted-dike sections respectively. A velocity filter (a cone of radius one wavelength, $200 \mathrm{~m}$ ) was applied. The base of the steep velocity gradient is similar to that obtained by the linear triangular filter of the geological boundary (white line). (b) and (c) Depth sections of the velocity model on- and off-axis (70 kyr) (solid line), their locations are shown in (a) as dark vertical lines. These are compared to the velocity-depth profiles determined at this latitude, ESP5 (off-axis, 180 kyr) and ESP1 (on-axis) (dashed line) [20]. Note the similarity in the thickness of the surficial low-velocity zone and the depth over which the steep velocity gradient extends.B(a) Velocity structure for a bimodal lava emplacement model run that fits the layer $2 \mathrm{~A}$ thicknesses measured on the CDP31 at $9^{\circ} 30^{\prime} \mathrm{N}$ EPR [28]. $\sigma_{i}=10 \mathrm{~m}, \sigma_{e S}=75 \mathrm{~m}, \sigma_{e L}=1500 \mathrm{~m}, t=1 \mathrm{~m}, \operatorname{minl}=1000 \mathrm{~m}$. Velocities of $2.2 \mathrm{~km} / \mathrm{s}$ (dark gray) and 5.5 $\mathrm{km} / \mathrm{s}$ (light gray) are assigned to the extrusive and sheeted dike sections, respectively. A velocity filter (a cone of radius one seismic wavelength, $67 \mathrm{~m}$ ) was applied. The base of the steep velocity gradient is similar to that obtained by the linear triangular filter of the geological boundary (white line). (b)-(d) Depth sections of the velocity model on-axis and at 10 and 20 kyr (solid line), their locations are shown in (a) as dark vertical lines. These are compared to the velocity-depth profiles determined at this latitude from the on-bottom refraction (NOBEL) experiment [36]. Note the similarity in the thickness of the surficial low-velocity zone and the depth over which the steep velocity gradient extends. 
on the EPR. The seismic velocity structure at this location is constrained by several expanding spread profiles (ESP) [20]. The geometry of the layer 2A boundary is constrained from a two-ship wide aperture profile (WAP) shot here [24]. We generate a model using the bimodal distribution of flows that fits the layer $2 \mathrm{~A}$ geometry in this area and assign velocities of $2.2 \mathrm{~km} / \mathrm{s}$ and $5.5 \mathrm{~km} / \mathrm{s}$ to the extrusives and sheeted dikes, respectively. The source used for the ESPs had a dominant frequency of 20 $\mathrm{Hz}$ corresponding to a wavelength of $200 \mathrm{~m}$ at 4 $\mathrm{km} / \mathrm{s}$. We therefore averaged our velocity structure using a cone-shaped filter with radius $200 \mathrm{~m}$ (Fig. $8 \mathrm{Aa}$ ) in order to compare it with the seismically derived velocity structure. The base of the resulting high gradient region closely resembles the result of running a one-dimensional triangular filter over the extrusive-dike contact. Velocity-depth profiles were constructed at ages of $0 \mathrm{kyr}$ and $70 \mathrm{kyr}$ (solid lines in Fig. 8A). They compare very well with the velocity-depth profiles obtained from the ESPs (dashed lines). There is no surficial low-velocity zone in the model for $0 \mathrm{kyr}$, while one is observed in ESP5. ESP5 may be located slightly off-axis, which would account for this discrepancy. ESP1 actually lies on $180 \mathrm{kyr}$ old crust but velocity profiles at 180 kyr and $70 \mathrm{kyr}$ are assumed to represent off-axis sections where crustal construction has been completed. The thickness, shape, and slope of the high gradient region is very similar to those measured with the ESPs.

The same procedure was applied to a second area at $9^{\circ} 30^{\prime} \mathrm{N}$ on the EPR, where the upper crustal velocity structure is constrained by a high-resolution on-bottom refraction experiment [36]. The geometry of layer 2A is determined from MCS line CDP31 [28]. The on-bottom refraction experiment used a source with a dominant frequency of $60 \mathrm{~Hz}$. A model was constructed to matched the line CDP31 and was filtered at a wavelength of $67 \mathrm{~m}$ (Fig. 8Ba). Again, depth sections through the resulting velocity model show a high velocity gradient very similar in thickness, shape, and slope to those measured in the on-bottom refraction experiment on crust 0,10 and 20 kyr (Fig. 8Bb-d).

The fact that the boundary between the sheeted dikes and extrusives is not seismically sharp is consistent with the multichannel data. The base of layer
$2 \mathrm{~A}$ is not imaged as a normal incidence reflection in the multichannel seismic data but, rather, is a diving ray which turns in a steep velocity gradient and is observed at larger offsets on the streamer as a wideangle 'reflection'/refraction. These observations support the idea that the boundary between the extrusives and sheeted dikes is not sharp on the scale of a quarter-wavelength $(\sim 50 \mathrm{~m})$. However, on the scale of a full wavelength a coherent steep velocity gradient is sensed, causing the rays to turn back to the surface and resulting in a wide-angle reflection. Therefore, in this case, one seismic wavelength is an estimate of the distance required for energy to refract in a steep velocity gradient and produce a turning ray.

The thickness of the seismic high velocity gradient predicted from the bimodal lava emplacement model depends on the thickness of the transition zone from extrusives to sheeted dikes and on the dominant wavelength of the experiment that is measuring the velocity structure. For a model with a wide transition region, as would be obtained for the unimodal lava emplacement model, a shorter seismic wavelength will give a sharp boundary but, laterally, it will be highly variable. A long seismic wavelength will average out the variability and give a thicker high velocity gradient than has been seismically observed. For a narrow transition region, the long wavelength energy will simply see a somewhat broader transition region than the shorter wavelength. Under the simple assumptions that we make here the velocity structure predicted from the bimodal lava emplacement model is consistent with the shallow crustal velocity structure measured at the EPR. At the same time, the higher resolution on-bottom refraction experiment resolved a thinner on-axis thickness of layer 2A than the MCS experiment (Fig. $8 \mathrm{Be}$ and $\mathrm{Ad}$, respectively), consistent with the bimodal lava emplacement model.

\subsection{Isochron dips and magnetic anomaly transition widths}

Lavas erupted on the seafloor are rapidly buried by subsequent flows and subside. In the unimodal lava emplacement model subsidence rates are 20 $\mathrm{mm} / \mathrm{yr}$, assuming full spreading rates of $150 \mathrm{~mm} / \mathrm{yr}$ for the southern EPR. For the bimodal lava emplace- 
ment model, the rates of subsidence are initially very high, $\sim 200 \mathrm{~mm} / \mathrm{yr}$ for the first $1.5 \mathrm{kyr}$, and then drop to $40-10 \mathrm{~mm} / \mathrm{yr}$ during the following $8-27$ kyr. The dips of isochrons are sensitive to the length of the lava flows and the amount of subsidence that occurs. In the unimodal lava emplacement model, dips are relatively steep throughout the extrusive section and vary from $\sim 0^{\circ}$, near the surface, to $\sim 30^{\circ}$ at depth (Fig. 3). For the bimodal lava emplacement models that we propose in this paper (Fig. $7 \mathrm{a}, \mathrm{c})$, the upper lavas, composed of the long flows, have very shallow dips, $0^{\circ}$ to $\sim 10-15^{\circ}$. At the boundary between the two lava types dips are $0^{\circ}$. In the lower extrusive section flow lengths are short and subsidence rates are high and the dips are extremely steep, $50-70^{\circ}$. In Iceland, lava flow dips are zero near the surface and increase with depth reaching $6^{\circ} 1500 \mathrm{~m}$ below the original top of the lava pile [43]. Considering the differences in extrusive thickness between Iceland and the EPR, these observations cannot differentiate between both modes of lava emplacement. The two models are distinguishable because, in the bimodal lava emplacement model, the dips are reduced to zero at the boundary between the upper and lower lavas. H. Schouten and E.E.E. Hooft (Two-layered structure of the pillow lavas in oceanic crust and ophiolites, manuscript in prep., 1996) find evidence of a bimodal dip structure in the paleomagnetic inclinations of several DSDP/ODP drill cores, suggesting that a bimodal emplacement of the upper oceanic crust also occurs at intermediate and slow spreading centers.

Work on the transition width of marine magnetic anomalies from deep-tow measurements on the Gorda Rise [4] suggest that the portion of the transition width due to constructional processes is $1.7 \mathrm{~km}$. Near-bottom magnetic profiles from ridges in the Pacific covering intermediate to fast spreading rates give an average half-width of crustal formation of 2-3 km [8]. Measurements made by Macdonald et al., [7] on the EPR $21^{\circ} \mathrm{N}$ give transition widths of $1-1.4 \mathrm{~km}$. For our bimodal lava emplacement model the dips of the isochrons vary with depth in the extrusive section. We have calculated the magnetic anomaly from the geometry of the bimodal lava emplacement model and compared it with the anomaly that would be obtained assuming the simple geometries of earlier models. The transition widths obtained, $\sim 2-3 \mathrm{~km}$, are similar to those observed. However, as mentioned before, these magnetic anomaly reversal data cannot resolve the relative contributions of the width of the intrusion zone and lava flow distribution to the lava emplacement process.

\subsection{Age of seafloor lavas}

Goldstein et al. [15] dated seafloor lavas on a transect across the EPR at $9^{\circ} 31^{\prime} \mathrm{N}$ and showed that these lavas were at least 20-70 kyr younger than the predicted age of the crust based on spreading rate (Fig. 9). They suggested that off-axis eruptions are probably the cause of these anomalously young ages, implying the existence of a comparatively broad (several kilometers half-width) zone of intrusion. However, if a significant proportion of the dikes are intruded over a wide zone, the extrusive-dike transition becomes much broader than is consistent with geological observations (Table 2).

In the emplacement model that we propose, the intrusion zone is very narrow (on the order of a few tens of meters) but the upper part of the extrusive section forms by flows that have been transported a long distance (up to several kilometers) off-axis from their point of eruption. These flows will have ages that are younger than the predicted age of the crust based on the spreading rate. From runs of the bimodal lava emplacement model that match the range of the seismically observed variation in layer $2 \mathrm{~A}$ thickness in the $9^{\circ} \mathrm{N}$ area on the EPR [24,28], we predict seafloor ages will average about $\sim 30-70$ kyr younger than the crustal spreading age (Fig. 9). This is in agreement with the anomalously young lavas dated by Goldstein et al. [15] (Fig. 9), however, the predicted ages are in general younger than those observed. The discrepancy between the model and the dating can be explained if a significant amount of the off-axis thickening occurs below the surface, by the intrusion of sills. Another possibility is that, if the time from melt segregation in the mantle to eruption on the surface is substantial, then the time since eruption is significantly overestimated by the uranium-series disequilibrium dating [15].

Due to the narrowness of the extrusive-dike transition and its minimal effect on the seismic layer $2 \mathrm{~A}$ thickening profile, we infer that the number of dikes 


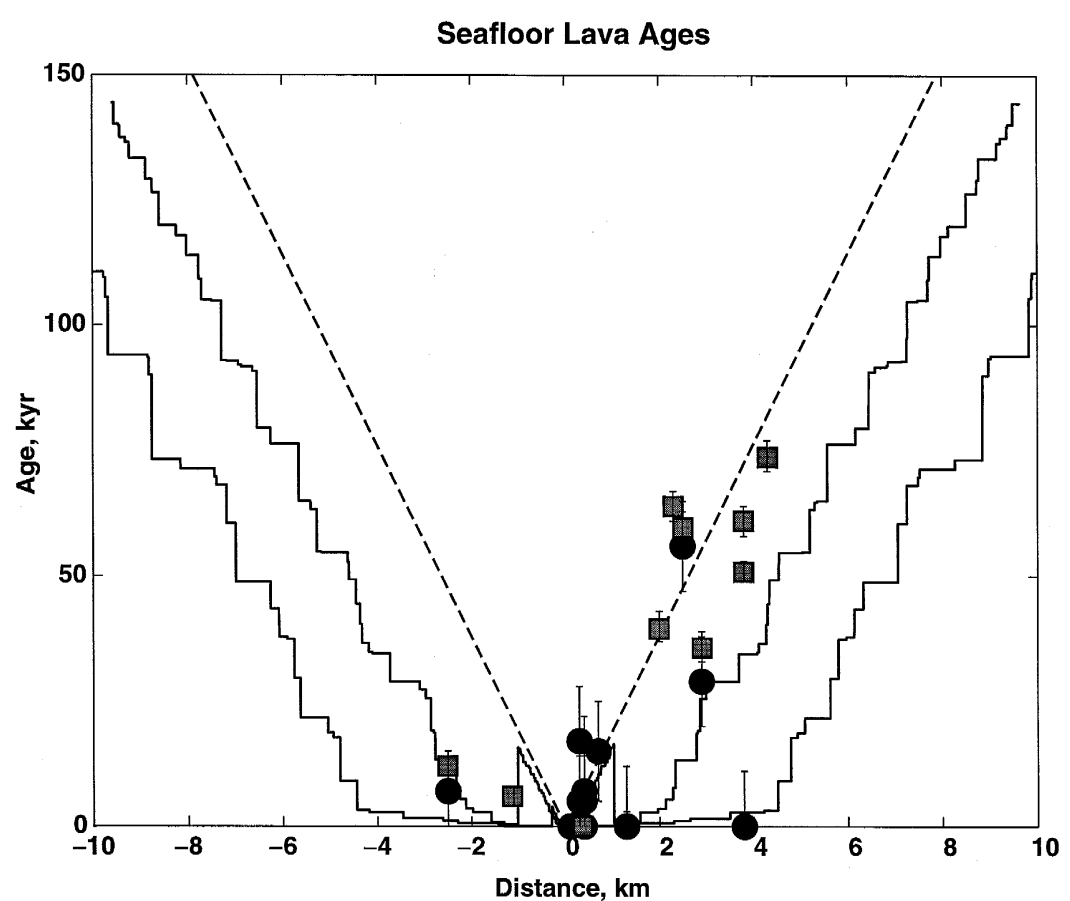

Fig. 9. Age offsets predicted by this model. The solid lines shows the ages of seafloor lavas determined from two bimodal lava emplacement models that match the range of layer $2 \mathrm{~A}$ thickening profiles measured in the $9^{\circ} \mathrm{N}$ area $[24,28]$ (Fig. 8Aa and $8 \mathrm{Ba}$ ). The dashed line is the predicted age of the seafloor based on the assumed half-spreading rate of $55 \mathrm{~mm} / \mathrm{yr}$. The seafloor ages are younger than predicted because young lavas flow out over older crust. Age offsets are $\sim 30-70 \mathrm{kyr}$. The age offsets of 20-70 kyr were observed at $9^{\circ} 31^{\prime} \mathrm{N}$ by Goldstein et al. [15] (circles $={ }^{230} \mathrm{Th}$ ages, squares $={ }^{231} \mathrm{~Pa}$ ages). Note that the bimodal lava emplacement model assumed a very narrow $(\sim 40 \mathrm{~m})$ intrusion zone. The anomalously young lava ages reported by Goldstein et al. [15] do not necessarily require a significant volume of eruptive activity outside the ASC, if lavas erupted in the ASC periodically spill out of the ASC and flow for considerable distances down the flanks of the axial high.

feeding any off-axis eruptions is minimal. The source region and crustal residence time of any off-axis eruptions may well be different from the on-axis eruptions, and so even small volumes of lavas erupted off-axis can explain the diverse compositions measured in off-axis sampling of seafloor basalts [10]. It is important to bear in mind that rare, and volumetrically insignificant, lavas erupting outside of the zone of lava emplacement will form a thin cover on the seafloor and have a high probability of being sampled. Thus, while it is possible that some lavas erupt off-axis, extensive off-axis eruptions are not necessarily required to explain the anomalously young age of seafloor lavas observed near the EPR.

The existence of a narrow dike intrusion zone is consistent with the observation that most hydrothermal activity along the northern and southern EPR is located within the ASC $[9,14]$. Hydrothermal activity is driven by a heat source, on short time scales by a dike, over long times by an underlying magma body. The predominance of hydrothermal activity within the ASC supports the assertion that the majority of dikes are intruded very close to the ridge axis. Lava flows in the bimodal lava emplacement model extend up to a few kilometers off-axis and are also consistent with the observation that sediment cover in the $9^{\circ} 30^{\prime} \mathrm{N}$ EPR area is anomalously low up to 3-4 $\mathrm{km}$ from the ridge axis, beyond which the sediment thickness increases dramatically [15]. The off-axis seafloor is covered by the lavas that have flooded out of the ASC. The ASC is filled by the more common events - short flows. This could explain the observation that most off-axis seafloor is covered by lobate lava flows, while the morphology within the ASC is more varied, consisting of pillows and sheet flows with extensive collapse features 
[9,53]. Extensive collapse within the ASC also supports the high subsidence rates predicted by the bimodal lava emplacement model near the rise crest.

\section{Conclusions}

A stochastic model of the emplacement of dikes and lava flows generates an upper oceanic crustal structure similar to that observed in ophiolites, in ocean drill holes and in seismic data from the East Pacific Rise. An emplacement model with a narrow intrusion zone (95\% of the dikes are intruded within a zone $40 \mathrm{~m}$ wide, centered on the ridge axis) and a bimodal emplacement of lavas can explain the variation in thickness of layer 2A observed seismically at the EPR and the sharpness of the extrusive-dike transition region observed in outcrop in ophiolites and on the seafloor. A thin, on-axis extrusive section is rapidly built up by accumulating a sequence of short flows erupted, and probably confined, within the ASC. The progressive thickening of the extrusive layer inferred from the deepening of the seismic $2 \mathrm{~A} / 2 \mathrm{~B}$ boundary over $1-3 \mathrm{~km}$ from the ridge axis is caused by longer flows that spill out of the ASC and down the flanks of the axial high or erupt off-axis (Fig. 6). In the resulting lava pile the upper part of the extrusive section is composed of flows deposited off the rise crest while the lower portion is flows deposited on-axis. This stochastic model for the construction of the upper crustal section is consistent with the velocity structure of the upper crust (producing a near-surface low velocity layer underlain by a steep velocity gradient), paleomagnetic inclinations in drill cores (a bimodal dip structure), magnetic transition widths $(\sim 2 \mathrm{~km})$, and age offsets of seafloor lavas relative to the underlying crust $(\sim 30$ $70 \mathrm{kyr})$. Extensive off-axis eruptions are not necessarily required to explain these age discrepancies. The similarity in seismic structure between the northern and southern EPR (full spreading rates of 110 and $150 \mathrm{~mm} / \mathrm{yr}$, respectively) indicate that the bimodal lava emplacement model is applicable to fast spreading ridges over a range of spreading rates.

\section{Acknowledgements}

Thanks to P. Buhl, R.S. Detrick, A.J. Harding, G.M. Kent, J.C. Mutter, and J.A. Orcutt for collect- ing the southern EPR multichannel seismic data set. We would like to thank Joe Cann for his help, especially with identifying the importance of the extrusive-dike transition thickness. Thanks to G.M. Kent and J. Escartín for helpful discussions. This manuscript was improved by thoughtful reviews by G. Christeson and A. Harding. This work was supported by NSF grant OCE-8020330. WHOI contribution number 9220. [CL]

\section{References}

[1] R.G.W. Kidd, A model for the process of formation of the upper oceanic crust, Geophys. J.R. Astron. Soc. 50, 149-183, 1977.

[2] J.R. Cann, A model for oceanic crustal structure developed, Geophys. J.R. Astron. Soc. 39, 169-187, 1974.

[3] G. Palmason, Kinematics and heat flow in a volcanic rift zone with application to Iceland, Geophys. J.R. Astron. Soc. 33, 451-481, 1973.

[4] T. Atwater and J.D. Mudie, Detailed near-bottom geophysical study of the Gorda Rise, J. Geophys. Res. 78, 8665-8686, 1973.

[5] H. Schouten and C.R. Denham, Modeling the oceanic magnetic source layer, in: Deep Drilling Results in the Atlantic Ocean: Ocean Crust, M. Talwani, C.G. Harrison and D.E. Hayes, eds., pp. 151-159, AGU Maurice Ewing Ser., Washington, DC, 1979.

[6] K. Macdonald, Near-bottom magnetic anomalies, asymmetric spreading, oblique spreading, and tectonics of the MidAtlantic Ridge near lat $37^{\circ} \mathrm{N}$, Geol. Soc. Am. Bull. 88, 541-555, 1977.

[7] K.C. Macdonald, S.P. Miller, S.P. Huestis and F.N. Spiess, Three-dimensional modeling of a magnetic reversal boundary from inversion of deep-tow measurements, J. Geophys. Res. 85, 3670-3680, 1980.

[8] K.D. Klitgord, S.P. Huestis, J.D. Mudie and R.L. Parker, An analysis of near-bottom magnetic anomalies: Sea-floor spreading and the magnetized layer, Geophys. J.R. Astron. Soc. 43, 387-424, 1975.

[9] R.M. Haymon, D.J. Fornari, K.L. Von Damm, et al., Volcanic eruption of the mid-ocean ridge along the East Pacific Rise crest at $9^{\circ} 45^{\prime}-52^{\prime} \mathrm{N}$ : Direct submersible observations of seafloor phenomena associated with an eruption event in April, 1991, Earth Planet. Sci. Lett. 119, 85-101, 1993.

[10] M.R. Perfit, D.J. Fornari, M.C. Smith et al., Small-scale spatial and temporal variations in mid-ocean ridge crest magmatic processes, Geology 22, 375-379, 1994.

[11] P. Lonsdale, Segmentation of the Pacific-Nazca Spreading Center, $1^{\circ} \mathrm{N}-20^{\circ} \mathrm{S}$, J. Geophys. Res. 94, 12,197-12,225, 1989.

[12] K. Macdonald, P.J. Fox, S. Miller, et al., The East Pacific Rise and its flanks $8-18^{\circ} \mathrm{N}$ : History of segmentation, propagation and spreading direction based on SeaMARC II and Sea Beam studies, Mar. Geophys. Res. 14, 299-344, 1992. 
[13] K.C. Macdonald and P.J. Fox, The axial summit graben and cross-sectional shape of the East Pacific Rise as indicators of axial magma chambers and recent volcanic eruptions, Earth Planet. Sci. Lett. 88, 119-131, 1988.

[14] D.J. Fornari and R.W. Embley, Tectonic and volcanic controls on hydrothermal processes at the mid-ocean ridge: An overview based on near-bottom and submersible studies, in: Seafloor Hydrothermal Systems: Physical, Chemical, Biological, and Geological Interactions, S.E. Humphris, R.A. Zierenberg, L.S. Mullineaux and R.E. Thomson, eds., pp. 1-46, Am. Geophys. Union, Washington, DC, 1995.

[15] S.J. Goldstein, M. Perfit, R. Batiza, et al., Off-axis volcanism at the East Pacific Rise detected by uranium-series dating of basalts, Nature 367, 157-159, 1994.

[16] R.N. Anderson, et al., The first reference section over $1 \mathrm{~km}$ through layer 2A of the oceanic crust, Nature 300, 589-594, 1982.

[17] J.S. Pallister, Structure of the sheeted dike complex of the Samail ophiolite near Idra, Oman, J. Geophys. Res. 86, 2661-2672, 1981.

[18] E. Rosencrantz, The structure of sheeted dikes and associated rocks in North Arm massif, Bay of Islands ophiolite complex, and the intrusive process at oceanic spreading centers, Can. J. Earth Sci. 20, 787-801, 1983.

[19] K.C. Macdonald, P.J. Fox, R.T. Alexander, et al., Volcanic growth faults and the origin of Pacific abyssal hills, Nature 380, 125-129, 1996.

[20] E.E. Vera, P. Buhl, J.C. Mutter, et al., The structure of 0-0.2 My old oceanic crust at $9^{\circ} \mathrm{N}$ on the East Pacific Rise from expanded spread profiles, J. Geophys. Res. 95, 15,52915,556, 1990.

[21] A.J. Harding, M.E. Kappus, J.A. Orcutt, et al., The structure of young oceanic crust at $13^{\circ} \mathrm{N}$ on the East Pacific Rise from ESPs, J. Geophys. Res. 94, 12163-12196, 1989.

[22] D.R. Toomey, G.M. Purdy, S.C. Solomon and W.S.D. Wilcock, The three-dimensional seismic velocity structure of the East Pacific Rise near latitude $9^{\circ} 30^{\prime} \mathrm{N}$, Nature 347, 639-645, 1990.

[23] J.S. McClain, J.A. Orcutt and M. Burnett, The East Pacific Rise in cross section: A seismic model, J. Geophys. Res. 90, 8627-8640, 1985.

[24] E.E. Vera and J.B. Diebold, Seismic imaging of oceanic layer $2 \mathrm{~A}$ between $9^{\circ} 30^{\prime} \mathrm{N}$ and $10^{\circ} \mathrm{N}$ on the East Pacific Rise from two-ship wide-aperture profiles, J. Geophys. Res. 99, 3031-3042, 1994.

[25] M.E. Kappus, A.J. Harding and J.A. Orcutt, a baseline for upper crustal seismic velocity variations along the East Pacific Rise at $13^{\circ} \mathrm{N}$, J. Geophys. Res. 100, 6143-6161, 1995.

[26] G.L. Christeson, G.M. Kent, G.M. Purdy and R.S. Detrick, Extrusive thickness variability at the East Pacific Rise 9$10^{\circ} \mathrm{N}$ : Constraints from seismic techniques, J. Geophys. Res., submitted.

[27] G.L. Christeson, G.M. Purdy and G.J. Fryer, Seismic constraints on shallow crustal emplacement processes at the fast spreading East Pacific Rise, J. Geophys. Res. 99, 17,95717,974, 1994.

[28] A.J. Harding, G.M. Kent and J.A. Orcutt, A multichannel seismic investigation of the upper crustal structure at $9^{\circ} \mathrm{N}$ on the East Pacific Rise: Implications for crustal accretion, J. Geophys. Res. 98, 13,925-13,944, 1993.

[29] G.M. Kent, A.J. Harding, J.A. Orcutt, et al., The uniform accretion of oceanic crust south of the Garrett Transform at $14^{\circ} 15^{\prime} \mathrm{S}$ on the East Pacific Rise, J. Geophys. Res. 99, 9005-9698, 1994.

[30] R.E. Houtz, Seismic properties of layer 2A in the Pacific, J. Geophys. Res. 81, 6321-6340, 1976.

[31] G.M. Purdy, New observations of the shallow seismic structure of young oceanic crust, J. Geophys. Res. 92, 9351-9362, 1987.

[32] R.D. Hyndman and M.J. Drury, The physical properties of oceanic basement rocks from deep drilling on the MidAtlantic Ridge, J. Geophys. Res. 95, 17417-17429, 1976.

[33] R.H. Wilkens, G.J. Fryer and J. Karsten, Evolution of porosity and seismic structure of the upper oceanic crust: Importance of aspect ratios, J. Geophys. Res. 96, 17,981-17,995, 1991.

[34] P. Berge, G. Fryer and R. Wilkens, Velocity-porosity relationships in the upper oceanic crust: Theoretical considerations, J. Geophys. Res. 97, 15,239-15,254, 1992.

[35] T.J. Herron, Lava flow layer — East Pacific Rise, Geophys. Res. Lett. 9, 17-20, 1982.

[36] G.L. Christeson, G.M. Purdy and G.J. Fryer, Structure of young upper crust at the East Pacific Rise near $9^{\circ} 30^{\prime} \mathrm{N}$, Geophys. Res. Lett. 19, 1045-1048, 1992.

[37] K.M.M. Rohr, B. Milkereit and C.J. Yorath, Asymmetric deep crustal structure across the Juan de Fuca Ridge, Geology, 16, 533-537, 1988.

[38] K. Becker and H. Sakai, et al., Proc. ODP Init. Rep. 111, Part A, 1988.

[39] J.C. Mutter, S.M. Carbotte, W. Su, et al., Seismic images of active magma systems beneath the East Pacific Rise between $17^{\circ} 05^{\prime}$ and $17^{\circ} 35^{\prime} \mathrm{S}$, Science $268,391-395,1995$.

[40] R.S. Detrick, A.J. Harding, G.M. Kent, et al., Seismic structure of the southern East Pacific Rise, Science 259, 499-503, 1993.

[41] E.E. Hooft, G.M. Kent and R.S. Detrick, Magmatic variability along the southern EPR, J. Geophys. Res., submitted.

[42] A. Nicolas, Structure of Ophiolites and Dynamics of Oceanic Lithosphere, 367 pp., Kluwer, Dordrecht, 1989.

[43] J.A. Karson, S.D. Hurst and P. Lonsdale, Tectonic rotations of dikes in fast-spreading oceanic crust exposed near Hess Deep, Geology 20, 685-688, 1992.

[44] J. Francheteau, R. Armijo, J.L. Cheminee, et al., 1 Ma East Pacific Rise oceanic crust and uppermost mantle exposed by rifting in Hess Deep (equatorial Pacific Ocean), Earth Planet. Sci. Lett. 101, 281-295, 1990.

[45] M. Cannat, V. Mamaloukas-Fangoulis, J.-M. Auzende et al., A geological cross-section of the Vema fracture zone transverse ridge, Atlantic ocean, J. Geodyn. 13, 97-118, 1991.

[46] D.D. Naidoo, J.R. Delaney and T. Juteau, A scarp-map profile of upper oceanic crust at the West Blanco Transform (WBT): insights into magmatic accretion, EOS, Trans. Am. Geophys. Union 73, 502, 1992. 
[47] R.G.W. Kidd, Modelling of processes at plate spreading boundaries, Ph.D. Thesis, Univ. East Anglia, 1976.

[48] S.J. Lippard, A.W. Shelton and I.G. Gass, The ophiolite of Northern Oman, Geol. Soc. London Mem. 11, 178, 1986.

[49] P.A. Cowie, C.H. Scholz, M. Edwards and A. Malinverno, Fault strain and seismic coupling at Mid-Ocean ridges, J. Geophys. Res. 98, 17,911-17,920, 1993.

[50] S.M. Carbotte and K.C. Macdonald, Comparison of seafloor tectonic fabric at intermediate, fast, and super fast spreading ridges: Influence of spreading rate, plate motions, and ridge segmentation on fault patterns, J. Geophys. Res. 99, 13,60913,632, 1994.
[51] G.M. Kent, A.J. Harding and J.A. Orcutt, Evidence for a smaller magma chamber beneath the East Pacific Rise at $9^{\circ} 30^{\prime} \mathrm{N}$, Nature 344, 650-653, 1990.

[52] T. Atwater, Constraints from the FAMOUS area concerning the structure of the oceanic section, in: Deep Drilling Results in the Atlantic Ocean: Ocean Crust, M. Tawani, C.G. Harrison and D.E. Hayes, eds., pp. 33-42, Am. Geophys. Union, Washington, DC, 1979.

[53] T.M. Shank, D.J. Fornari, R.A. Lutz, et al., Establishment of a long-term observatory at nascent hydrothermal vents on the East Pacific Rise at $9^{\circ} 49^{\prime}-50^{\prime} \mathrm{N}$ : Baseline observations, J. Geophys. Res., submitted, 1995. 